\title{
Stabilizing Highly Dispersed Halo Sites in Thermally Restructured Palladium Core@ @hell Nanoparticles for Improved Catalyst Activity and Durability
}

\author{
Alexander J. Hill, Adarsh Bhat, Zachary J. Berquist, Galen B. Fisher, Andrej Lenert*, Johannes \\ W. Schwank* \\ Department of Chemical Engineering, University of Michigan, Ann Arbor, Michigan 48109, \\ United States
}

\begin{abstract}
Stabilizing high dispersions of catalytically active metals is integral to improving the lifetime, activity, and material utilization of catalysts that are periodically exposed to high temperatures during operation or maintenance. We have found that annealing palladium-based core@shell catalysts in air at elevated temperature $\left(800^{\circ} \mathrm{C}\right)$ promotes the redispersion of active metal into highly dispersed sites, which we refer to as halo sites. Here, we examine the restructuring of $\mathrm{Pd} @ \mathrm{SiO}_{2}$ and $\mathrm{Pd} @ \mathrm{CeO}_{2}$ core@ shell catalysts over successive $800^{\circ} \mathrm{C}$ aging cycles to understand the formation, activity, nanoscale structure and stability of these palladium halo sites. While encapsulation generally improves metal utilization by providing a physical barrier that promotes redispersion over agglomeration, our cycled aging experiments demonstrate that halo sites are not stable in all catalysts. Halo sites continue to migrate in $\mathrm{Pd} @ \mathrm{SiO}_{2}$ due to poor metalsupport bonding, which leads to palladium agglomeration. In contrast, halo sites formed in $\mathrm{Pd} @ \mathrm{CeO}_{2}$ remain stable. The dispersed palladium also synergistically stabilizes the ceria from agglomerating. We attribute this stability, in addition to an observed improvement in catalytic activity, to the coordination between palladium and reducible ceria that arises during the formation of halo sites. We probe the importance of ceria oxidation state on the stability of halo sites by aging $\mathrm{Pd} @ \mathrm{CeO}_{2}$ after it has been reduced. While some halo sites agglomerate, we find that returning to air aging mitigates the loss of these sites and catalytic activity. Our findings illustrate how nanoscale catalyst structures can be designed to promote the formation of highly stable and dispersed metal sites.
\end{abstract}

Keywords: core@shell catalyst, metal utilization, low-temperature activity, thermal stability, redispersion, $\mathrm{CO}$ oxidation

\section{INTRODUCTION}

Dynamic nanoscale restructuring of catalysts is common in many industrial applications which involve high-temperature conditions during synthesis or operation and maintenance such as catalytic converters, fuel cells, and steam reforming. ${ }^{1-3}$ In addition to its industrial relevance, studying catalyst restructuring at high temperatures also provides insight into long-term stability. Typically, the inherent surface energy of metal clusters drives thermally-induced restructuring towards unfavorable outcomes, whereby both the active metals and the metal oxide support agglomerate in a process known as sintering. ${ }^{4,5}$ This compromises reactant accessibility to active sites, intrinsic activity and consequently, the ability to utilize costly catalytic materials.

In contrast, favorable restructuring outcomes enhance overall activity by improving the dispersion of active metal species on support structures. Several methods have been developed to achieve such favorable restructuring. For example, controlling aging conditions to favor rapid heating and cooling cycles can drive metal disintegration and fast migration without promoting 
agglomeration. ${ }^{6,7}$ Additional chemical treatments using halogenated compounds have also been shown to drive the decomposition of larger clusters into highly dispersed and active configurations. ${ }^{8,9}$ However, catalyst deactivation on-stream due to thermal degradation tends to be unidirectional, and methods that reverse such processes have remained elusive. As such, it is important to continue developing methods that can achieve favorable nanoscale restructuring by directly using conditions that are intrinsic to and compatible with industrial applications. While some work has been done to achieve such outcomes, ${ }^{10-12}$ the challenge remains to achieve long term stability of favorably restructured catalysts under the transient gas compositions and temperature profiles encountered in industrially-relevant applications.

To mitigate the processes that cause sintering, core@shell catalyst designs have been proposed to explicitly separate active metal domains from one another through encapsulation by a porous shell support. ${ }^{13,14}$ We have recently shown that such core@ shell architectures can facilitate favorable and counter-intuitive restructuring when exposed to the high-temperature $\left(800^{\circ} \mathrm{C}\right)$ conditions common to many catalytic applications. ${ }^{15,16}$ Specifically, we discovered that core Pd disintegrated and migrated outward into the encapsulating shell, nearly doubling the number of available sites for reaction. The resulting highly dispersed Pd species formed an arrangement that resembled a "halo" around the original location of the core. The formation of these halo sites, which occurred within reducible $\mathrm{CeO}_{2}$ and nonreducible $\mathrm{SiO}_{2}$ shells, significantly improved active metal utilization and low-temperature activity in a probe $\mathrm{CO}$ oxidation reaction. Notably, the improvement was more significant in $\mathrm{Pd} @ \mathrm{CeO}_{2}$ catalysts compared to $\mathrm{Pd} @ \mathrm{SiO}_{2}$. This was due to the combination of greater redispersion of core $\mathrm{Pd}$, and changes in $\mathrm{Pd}$ oxidation state and coordination, which improved the recruitment and activation of lattice oxygen in the reducible $\mathrm{CeO}_{2}$ support as part of highly active Mars van Krevelen (MvK) oxidation mechanisms. ${ }^{16-18}$ In contrast, $\mathrm{Pd} / \mathrm{CeO}_{2}$ catalysts, which were prepared by impregnating $\mathrm{Pd}$ on the external surface of $\mathrm{CeO}_{2}$ nanospheres, underwent significant sintering when exposed to identical high-temperature aging conditions. This sintering decreased lattice oxygen recruitment, catalytic performance and ultimately, the utilization of $\mathrm{Pd}$ metal. The divergent restructuring behaviors exhibited by core@shell and surface-decorated structures emphasized that the initial nanoscale morphology influences the restructuring trajectory of a catalyst during high-temperature exposure. Specifically, it appears that encapsulating core@shell morphologies can act as a structural template that directs favorable restructuring outcomes in conditions that would typically deactivate a catalyst.

Despite the potential of leveraging core@shell architectures to drive favorable restructuring on-stream, the long-term stability of these halo sites remains uncertain. To address this question, here, we study the formation, activity, and structural stability of Pd halo sites in core@shell configurations over successive high-temperature aging cycles. Specifically, we examine the morphology and catalytic performance of three catalyst systems with comparable initial $\mathrm{Pd}$ dispersion, in between sequential 4-hour cycles of $800^{\circ} \mathrm{C}$ aging in air as summarized in Scheme 1. Pd@ $\mathrm{CeO}_{2}$ catalysts are compared to (1) Pd surface decorated on $\mathrm{CeO}_{2}\left(\mathrm{Pd} / \mathrm{CeO}_{2}\right)$ to understand the role of active metal placement, specifically encapsulation, and (2) $\mathrm{Pd} @ \mathrm{SiO}_{2}$ to understand the role of encapsulating shell chemistry and morphology, as polycrystalline $\mathrm{CeO}_{2}$ and amorphous $\mathrm{SiO}_{2}$ exhibit significant differences in their reducibility and porous nanoscale structure. We use a suite of analysis techniques that includes scanning and conventional transmission electron microscopy (STEM, TEM), x-ray energy dispersive spectroscopy (EDS), $\mathrm{N}_{2}$ physisorption for surface area analysis, $\mathrm{CO}$ chemisorption, thermogravimetric analysis (TGA), $\mathrm{x}$ ray photoelectron spectroscopy (XPS) and x-ray powder diffraction (XRD) to obtain structural and morphological insights. $\mathrm{CO}$ oxidation serves as a probe reaction due to its relevance in industrial 
catalytic settings, such as vehicle emission control and preferential oxidation for renewable hydrogen production. ${ }^{19-21} \mathrm{CO}$ oxidation probe reactions can also extract structural information and examine the recruitment of lattice oxygen. ${ }^{17,18,21}$

Our investigation into the nanoscale structure of the aged catalysts identifies that encapsulation and support chemistry are key to mediating the formation and trapping of Pd halo sites. Encapsulation appears to shift the dominant thermal restructuring pathway away from whole particle migration to the emission-limited transport of smaller, mobile species. This transport process, coupled with the tortuous nature of the shell support, increases the likelihood that mobile species do not locally interact and agglomerate and instead become trapped on the support as halo sites with high dispersion and catalytic activity. While both $\mathrm{SiO}_{2}$ and $\mathrm{CeO}_{2}$ shells facilitate the formation of dispersed metal sites, ${ }^{11,22-24}$ we show here that only $\mathrm{Pd} @ \mathrm{CeO}_{2}$ can retain its favorable catalytic activity after sequential cycles of $800^{\circ} \mathrm{C}$ aging. $\mathrm{Pd} @ \mathrm{SiO}_{2}$ in contrast, exhibits continued mobility of dispersed $\mathrm{Pd}$ during repeated aging, which results in agglomeration on the external surface of the $\mathrm{SiO}_{2}$ shell support. The improved stability and retention of activity in $\mathrm{Pd} @ \mathrm{CeO}_{2}$ is due to the strong anchoring of $\mathrm{Pd}$ halo sites on the $\mathrm{CeO}_{2}$ support, which synergistically stabilizes the $\mathrm{CeO}_{2}$ domains. We subsequently age the restructured $\mathrm{Pd} @ \mathrm{CeO}_{2}$ catalyst in pure $\mathrm{N}_{2}$ after it has been reduced under the flow of excess $\mathrm{CO}$ to further probe the stability limits of halo sites. These conditions result in some agglomeration of $\mathrm{Pd}$ halo sites and loss of catalytic activity, which emphasizes the importance of support chemistry for forming and stabilizing highly dispersed active sites. We demonstrate, however, that returning to $800^{\circ} \mathrm{C}$ air aging conditions can recover halo sites and low-temperature activity. Thus, in addition to probing the applicability of core@shell architectures in catalytic settings that require exposure to high-temperature conditions, this work offers insights into how core@shell nanostructures can be more generally designed and aged to facilitate favorable restructuring that improves both material utilization and robustness.

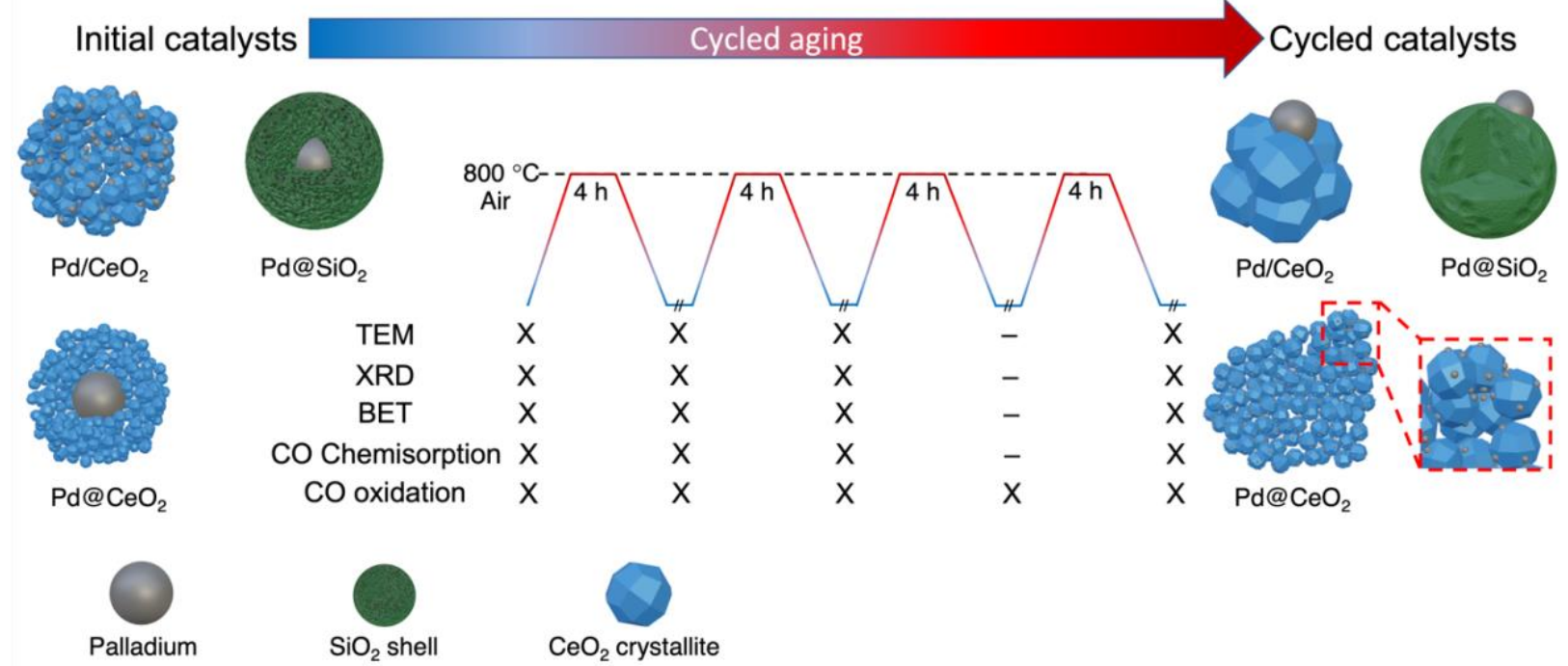

Scheme 1. Graphical overview of cycled aging study. $\mathrm{Pd} @ \mathrm{CeO}_{2}, \mathrm{Pd} @ \mathrm{SiO}_{2}$, and $\mathrm{Pd} / \mathrm{CeO}_{2}$ catalysts are subjected to four sequential cycles aging at $800^{\circ} \mathrm{C}$ in air for 4 hours to examine $\mathrm{Pd}$ transport and trapping in various catalytic architectures. A suite of structural analysis techniques complements $\mathrm{CO}$ oxidation activity measurements prior to each aging cycle to understand better how morphology can be used to direct catalyst restructuring and improve material utilization.

RESULTS AND DISCUSSION

Defining Model Catalyst Systems 
The three model catalyst systems prior to cycled aging (referred to as initial catalysts) are shown in the first column of Figure 1. We note that these catalysts were prepared following previously described methods ${ }^{15,16,25}$ and have been exposed to $500^{\circ} \mathrm{C}$ in air for 2 hours (see Methods Section for more information). The $\mathrm{Pd} @ \mathrm{SiO}_{2}$ and $\mathrm{Pd} @ \mathrm{CeO}_{2}$ have comparable $\mathrm{Pd}$ core size on the order of $3-5 \mathrm{~nm}$ in diameter and similar oxide shell thickness of approximately $10-12 \mathrm{~nm}$. The overall core@shell structures have total diameters on the order of $20-25 \mathrm{~nm}$. $\mathrm{CO}$ chemisorption confirms that all catalysts exhibit similar initial Pd dispersion values between 32 and $36 \%$. Meanwhile, XRD analysis of the initial $\mathrm{Pd} @ \mathrm{CeO}_{2}$ and $\mathrm{Pd} / \mathrm{CeO}_{2}$ demonstrates a slight difference in the $\mathrm{CeO}_{2}$ crystallite size as calculated by the Debye-Scherrer Equation. The crystallites in the encapsulated catalyst are smaller $(\sim 4 \mathrm{~nm})$ than those in the conventionally prepared system $(\sim 8 \mathrm{~nm})$. This data is summarized in Table 1 . See Figure $\mathrm{S} 1-\mathrm{S} 4$ for additional microscopy characterization of the model catalysts before and after aging.

The comparable size of the core and shell domains in $\mathrm{Pd} @ \mathrm{SiO}_{2}$ and $\mathrm{Pd} @ \mathrm{CeO}_{2}$ are contrasted by differences in the morphology of the encapsulating shells. $\mathrm{SiO}_{2}$ shells exist as single, porous encapsulating envelopes. The formation of these envelopes is due to the way that silicatebased precursors, such as tetraethyl orthosilicate (TEOS, which is used here), undergo polymerization into a unified structure around a surfactant micelle as they proceed through stages of homogeneous and heterogeneous nucleation. ${ }^{26}$ In contrast, $\mathrm{CeO}_{2}$ shells form through the stacking of smaller $\mathrm{CeO}_{2}$ crystallites, which are approximately $3-5 \mathrm{~nm}$ in size (Figure 1 and $\mathrm{S} 1$, S3). Precursors that strongly coordinate $\mathrm{Ce}^{4+}$ ions, ${ }^{27}$ such as cerium-atrane (used here), provide a degree of steric hindrance to mitigate agglomeration into larger crystals and facilitate slow hydrolysis. This process increases the likelihood that $\mathrm{CeO}_{2}$ crystallites form around $\mathrm{Pd}$ core seeds through surfactant-mediated interactions instead of quickly hydrolyzing into larger $\mathrm{CeO}_{2}$ structures that do not adequately encapsulate $\mathrm{Pd}$. The packing of these smaller $\mathrm{CeO}_{2}$ grains creates void spaces that provide the shell with its porosity and facilitates reactant accessibility to the active metal. These differences in shell morphology appear responsible for the different BET surface areas of the initial $\mathrm{Pd} @ \mathrm{CeO}_{2}$ and $\mathrm{Pd} @ \mathrm{SiO}_{2}$, which are 131 and $296 \mathrm{~m}^{2} / \mathrm{g}$, respectively. $\mathrm{Pd} / \mathrm{CeO}_{2}$, whose support also consists of stacks of smaller $\mathrm{CeO}_{2}$ crystallites, has a surface area of $150 \mathrm{~m}^{2} / \mathrm{g}$. This surface area is comparable to $\mathrm{Pd} @ \mathrm{CeO}_{2}$ (see Table 1).

Overall, these well-defined structures facilitate a direct comparison of how active metal placement, support shell morphology, and the chemical differences between nonreducible $\mathrm{SiO}_{2}$ and reducible $\mathrm{CeO}_{2}$ affect the formation and stability of $\mathrm{Pd}$ halo sites during high-temperature exposure. 


\section{Initial}
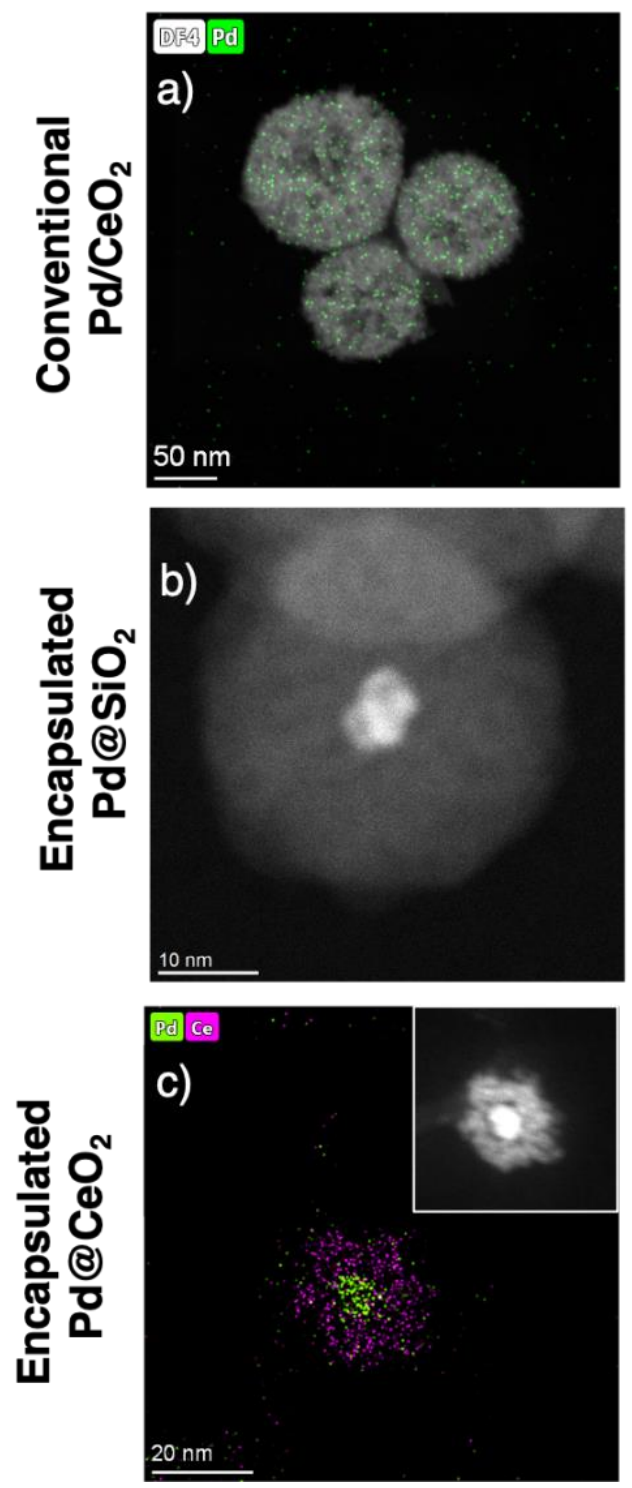

$800{ }^{\circ} \mathrm{C}$ aging

first cycle
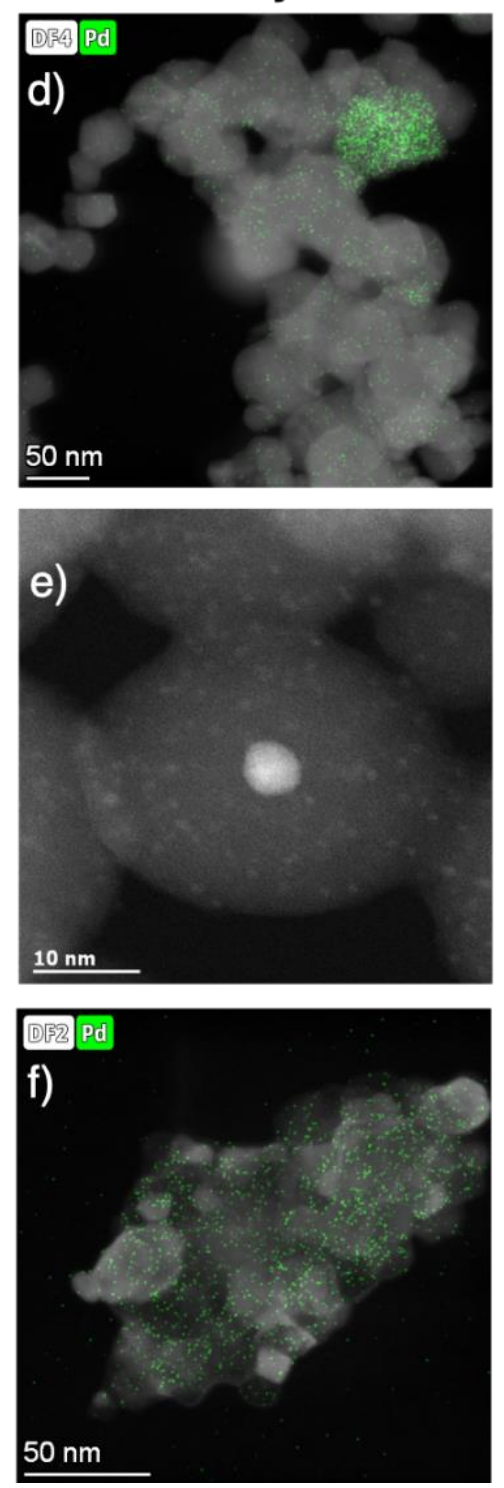

$800^{\circ} \mathrm{C}$ aging fourth cycle
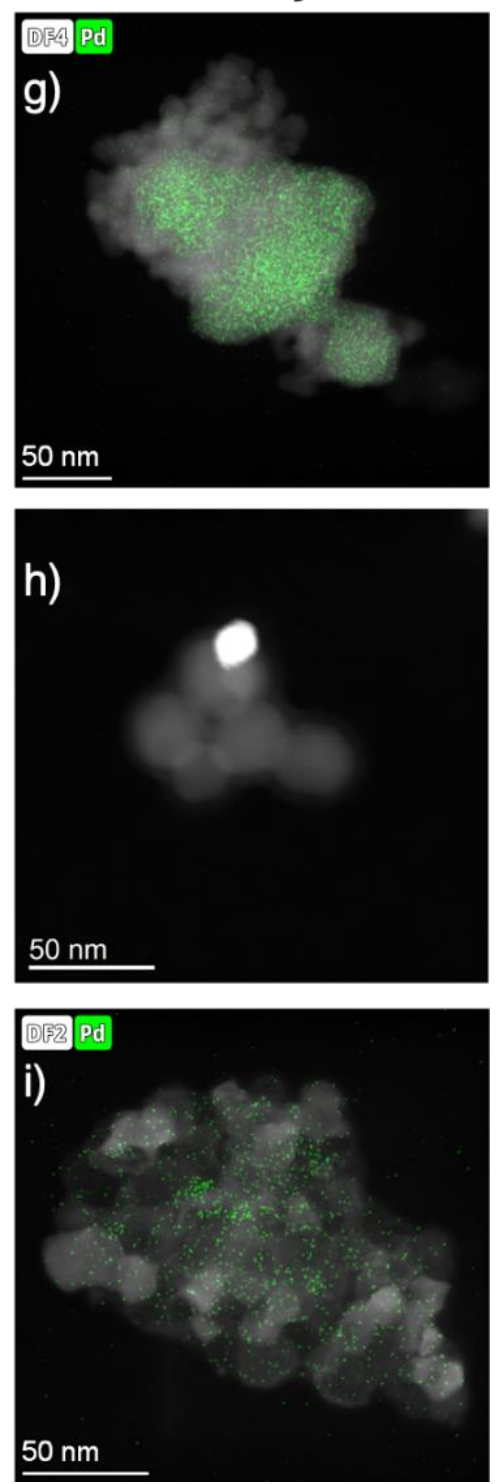

Figure 1. Distribution of Pd on initial and cycled catalysts. Electron microscopy characterization of encapsulated $\mathrm{Pd} / \mathrm{CeO}_{2}, \mathrm{Pd} @ \mathrm{SiO}_{2}$, and $\mathrm{Pd} @ \mathrm{CeO}_{2}$ as synthesized $(\mathrm{a}-\mathrm{c})$, and after one $(\mathrm{d}-\mathrm{f})$ and four $(\mathrm{g}-\mathrm{i})$ repeated cycles of 4-hour aging at $800^{\circ} \mathrm{C}$ in air. EDS elemental mapping has been included for $\mathrm{Pd} / \mathrm{CeO}_{2}$ and $\mathrm{Pd} @ \mathrm{CeO}_{2}$ due to poor Z-contrast between $\mathrm{Pd}$ and $\mathrm{Ce}$. Embedded legends on each Figure indicate the corresponding colors for the elemental maps (Pd: Green, Ce: Pink) and the detector used to collect the STEM image (DF: Dark-field). The overlay elemental map of Pd and $\mathrm{Ce}$ has been included for initial $\mathrm{Pd} @ \mathrm{CeO}_{2}$ to demonstrate the relative placement of active metal and support domains as synthesized. The dark-field image that corresponds to the elemental map of the initial $\mathrm{Pd} @ \mathrm{CeO}_{2}$ is inset. 
Table 1. Catalytic performance and structural features of bare $\mathrm{CeO}_{2}, \mathrm{Pd} / \mathrm{CeO}_{2}, \mathrm{Pd} @ \mathrm{SiO}_{2}$, and $\mathrm{Pd} @ \mathrm{CeO}_{2}$ catalysts as a function of the number of 4 -hour $800^{\circ} \mathrm{C}$ aging cycles in air.

\begin{tabular}{|c|c|c|c|c|c|}
\hline & & No. & Ir 800 & sing $\mathbf{c}$ & \\
\hline & & 0 (Initial) & 1 & 2 & 4 \\
\hline & $\mathrm{CeO}_{2}$ crystallite size $(\mathrm{nm})$ & 6.4 & 30.4 & 32.8 & 34.2 \\
\hline & BET surface area $\left(\mathrm{m}^{2} / \mathrm{g}\right)$ & 164 & 18 & 8 & 5 \\
\hline & $\mathrm{T}_{90}\left({ }^{\circ} \mathrm{C}\right)$ & 150 & 177 & 199 & 210 \\
\hline & Pd dispersion (\%) & 31.8 & 10.0 & 8.6 & 5.9 \\
\hline $1 \mathrm{a} / \mathrm{C} \mathrm{C}_{2}$ & $\mathrm{CeO}_{2}$ crystallite size $(\mathrm{nm})$ & 7.8 & 21.6 & 25.3 & 26.6 \\
\hline & BET surface area $\left(\mathrm{m}^{2} / \mathrm{g}\right)$ & 150 & 33 & 17 & 11 \\
\hline & $\mathrm{T}_{90}\left({ }^{\circ} \mathrm{C}\right)$ & 186 & 177 & 193 & 197 \\
\hline $\mathrm{Pd} @ \mathrm{SiO}_{2}$ & Pd dispersion (\%) & 35.9 & 61.9 & 25.3 & 11.1 \\
\hline & BET surface area $\left(\mathrm{m}^{2} / \mathrm{g}\right)$ & 296 & 117 & 50 & 32 \\
\hline & $\mathrm{T}_{90}\left({ }^{\circ} \mathrm{C}\right)$ & 153 & 103 & 102 & 103 \\
\hline & Pd dispersion (\%) & 32.8 & 88.4 & 85.7 & 83.7 \\
\hline 1 दो & $\mathrm{CeO}_{2}$ crystallite size $(\mathrm{nm})$ & 3.9 & 6.4 & 6.5 & 8.2 \\
\hline & BET surface area $\left(\mathrm{m}^{2} / \mathrm{g}\right)$ & 131 & 72 & 63 & 40 \\
\hline
\end{tabular}

\section{Identifying Activity and Stability Limits Through Cycled Aging}

$\mathrm{CO}$ oxidation was used as a probe reaction to monitor how nanoscale restructuring affected catalytic performance, as it is particularly sensitive to active site abundance and active site recruitment of lattice oxygen at the metal-support interface when reducible oxide supports, such as $\mathrm{CeO}_{2}$, are present. ${ }^{17,18}$ The rate of $\mathrm{CO}$ oxidation at $40^{\circ} \mathrm{C}$, as displayed in Figure 2a, was normalized by the total mass of Pd present in the catalyst and examined before and after the first cycle of $800^{\circ} \mathrm{C}$ aging to probe how thermally induced restructuring affected Pd utilization. As a commonly used measure of catalytic activity, ${ }^{28}$ the temperature required for $90 \%$ conversion of $\mathrm{CO}$, also known as the light-off temperature, or $\mathrm{T}_{90}$, was used to examine structural and functional stability over the four sequential $800^{\circ} \mathrm{C}$ aging cycles (Figure 2b). See Methods Section for more detail on catalytic testing and Figure S5-S7 for corresponding light-off curves. As seen in Figure 2, Pd@ $\mathrm{SiO}_{2}$ exhibited the poorest utilization of Pd among the initial catalysts, which coincided with the highest $\mathrm{T}_{90}\left(186^{\circ} \mathrm{C}\right)$. This high $\mathrm{T}_{90}$ is attributed to the fact that $\mathrm{Pd}_{0} @ \mathrm{SiO}_{2}$ does not contain a reducible oxide component, thereby impeding the possibility of high-activity $\mathrm{MvK}$ oxidation mechanisms. ${ }^{18}$ Instead, $\mathrm{CO}$ oxidation on $\mathrm{Pd} @ \mathrm{SiO}_{2}$ occurs via Langmuir-Hinshelwood kinetics, which requires the dissociative adsorption of gas-phase $\mathrm{O}_{2}$. The $\mathrm{CeO}_{2}$-containing $\mathrm{Pd} / \mathrm{CeO}_{2}$ exhibited a lower $\mathrm{T}_{90}\left(150^{\circ} \mathrm{C}\right)$ and a higher rate of $\mathrm{CO}_{2}$ production, normalized by its $\mathrm{Pd}$ content, which suggests a greater utilization of the active metal present. $\mathrm{Pd} @ \mathrm{CeO}_{2}$ exhibited the greatest $\mathrm{Pd}$ utilization among the initial catalysts, with a mass-normalized $\mathrm{CO}_{2}$ production rate almost one and a half times greater than that observed on conventional $\mathrm{Pd} / \mathrm{CeO}_{2}$. It is possible that $\mathrm{CeO}_{2}$ encapsulation, which has been shown to enhance interfacial contact, ${ }^{29}$ improved the recruitment of lattice oxygen and consequently, the rate of oxidation at low temperatures. 
However, the $\mathrm{T}_{90}$ for the initial $\mathrm{Pd} @ \mathrm{CeO}_{2}\left(153^{\circ} \mathrm{C}\right)$ was similar to $\mathrm{Pd} / \mathrm{CeO}_{2}\left(150^{\circ} \mathrm{C}\right)$. This is likely due to the autocatalytic nature of exothermic $\mathrm{CO}$ oxidation as the reaction temperature increases. ${ }^{30}$

a)

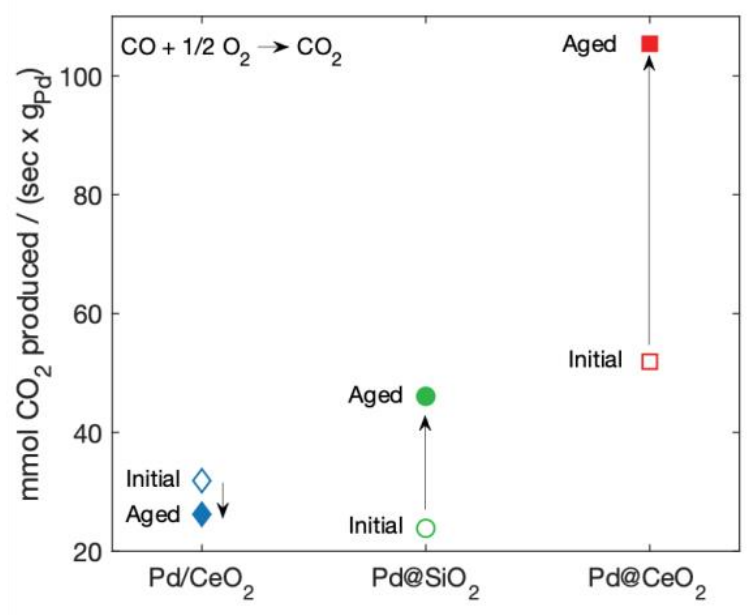

b)

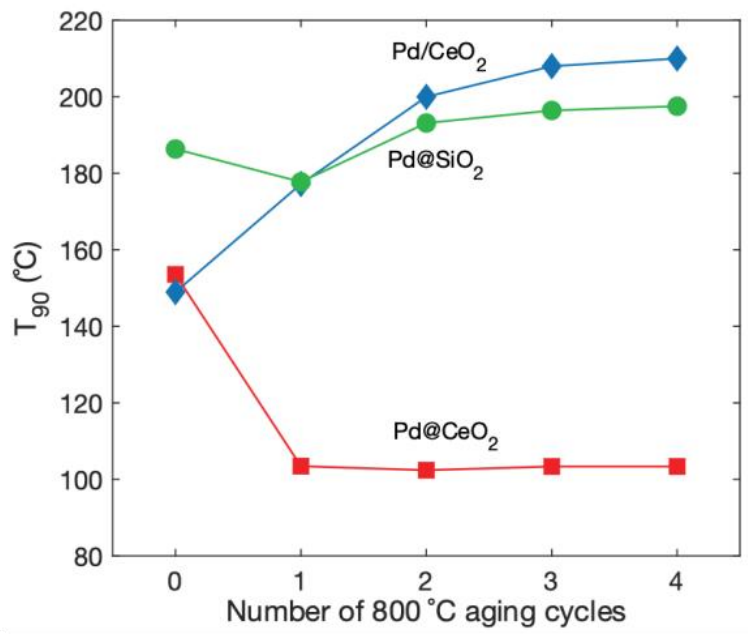

Figure 2. Effects of cycled aging on $\mathrm{Pd}$ utilization and $\mathrm{T}_{90}$ for $\mathrm{CO}$ oxidation. Rate of $\mathrm{CO}_{2}$ production at $40^{\circ} \mathrm{C}$, normalized by the mass content of $\mathrm{Pd}$, for $\mathrm{Pd} / \mathrm{CeO}_{2}$ and encapsulated $\mathrm{Pd} @ \mathrm{SiO}_{2}$ and $\mathrm{Pd} @ \mathrm{CeO}_{2}$ as-synthesized and after one cycle of aging (a). Temperature for $90 \%$ conversion of $\mathrm{CO}\left(\mathrm{T}_{90}\right)$ for conventional $\mathrm{Pd} / \mathrm{CeO}_{2}$ and encapsulated $\mathrm{Pd} @ \mathrm{SiO}_{2}$ and $\mathrm{Pd} @ \mathrm{CeO}_{2}$ as a function of the number of 4-hour $800^{\circ} \mathrm{C}$ aging cycles in air (b).

\section{Adverse Restructuring in Conventionally Prepared $\mathrm{Pd} / \mathrm{CeO}_{2}$}

As demonstrated in Figure 3, cycled aging at $800^{\circ} \mathrm{C}$ revealed diverging trends in the relative stability of the three restructured catalysts. $\mathrm{Pd}$ in the conventionally prepared, surfaceimpregnated $\mathrm{Pd} / \mathrm{CeO}_{2}$ underwent significant sintering, consistent with our previous observations. ${ }^{15,16} \mathrm{Pd}$ dispersion in $\mathrm{Pd} / \mathrm{CeO}_{2}$ decreased from 31.8 to $10.0 \%$, and average $\mathrm{CeO}_{2}$ crystallite size increased over two and a half times, from 7.8 to $21.6 \mathrm{~nm}$. The release of atomic oxygen from the lattice of reducible $\mathrm{CeO}_{2}$, which dramatically affects catalytic performance, is particularly sensitive to changes in active metal dispersion and $\mathrm{CeO}_{2}$ crystallite size. ${ }^{31}$ As such, we used TGA experiments to probe how thermal restructuring affected the ease of oxygen release from the $\mathrm{CeO}_{2}$ lattice. This data is shown in Figure S8. Pd/CeO 2 and $\mathrm{Pd} @ \mathrm{CeO}_{2}$ initially have comparable amounts of lattice oxygen released per mass of catalyst. This agrees well with the similar T90 values of the initial $\mathrm{Pd} / \mathrm{CeO}_{2}$ and $\mathrm{Pd} @ \mathrm{CeO}_{2}$ catalysts as shown in Figure $2 \mathrm{~b}$. The total oxygen released from $\mathrm{Pd} / \mathrm{CeO}_{2}$ however, decreased over three and a half times from 0.696 to 0.198 $\mathrm{mmol} \mathrm{O}$ released $/ \mathrm{g}_{\text {cat }}$ after the first cycle of $800^{\circ} \mathrm{C}$ aging in air. This suggests that the adverse sintering of $\mathrm{Pd}$ and $\mathrm{CeO}_{2}$ in the conventionally-prepared catalyst has impeded the recruitment of lattice oxygen. This loss in utilization coincided with a T90 that increased from 150 to $177^{\circ} \mathrm{C}$.

It should be noted that the crystallite growth of $\mathrm{Pd} / \mathrm{CeO}_{2}$ was less than that exhibited by a control sample of bare $\mathrm{CeO}_{2}$, whose domains grew from 6.4 to $30.4 \mathrm{~nm}$ after $800^{\circ} \mathrm{C}$ aging. There was also better retention of porosity in $\mathrm{Pd} / \mathrm{CeO}_{2}\left(33 \mathrm{~m}^{2} / \mathrm{g}\right)$ compared to bare $\mathrm{CeO}_{2}\left(18 \mathrm{~m}^{2} / \mathrm{g}\right)$ after aging (Table 1). This suggests that the presence of active metal can impede support sintering at elevated temperatures. It is possible that the stabilization of $\mathrm{CeO}_{2}$ in the conventional catalyst was conferred by some Pd species that remained dispersed, as seen in EDS analysis (Figure 1). Such observations have been corroborated in recent work by Datye et al., which demonstrated that atomically dispersed metal dopants can stabilize the surface area of $\mathrm{CeO}_{2}$ amidst high-temperature aging. ${ }^{32}$ As demonstrated in recent experimental and computational work, metal species can become stabilized or trapped on the surface of $\mathrm{CeO}_{2}$ supports in high dispersions during periods 
of thermally-induced mobility. The reducibility of $\mathrm{CeO}_{2}$ facilitates this trapping, as dispersed active metal species can form strong chemical bonds with undercoordinated $\mathrm{Ce}^{3+} .{ }^{11,33-35}$ While $\mathrm{Pd}$ species trapped on $\mathrm{CeO}_{2}$ exhibit high energetic barriers for mobility, the observation of sintered Pd by EDS, and increased $T_{90}$ after aging support that placing Pd active sites in close proximity through surface decoration promotes sintering over redispersion and trapping at high temperatures. This is consistent with other works which have shown that the initial placement of active metal readily implicates thermal stability. ${ }^{36,37}$

a)

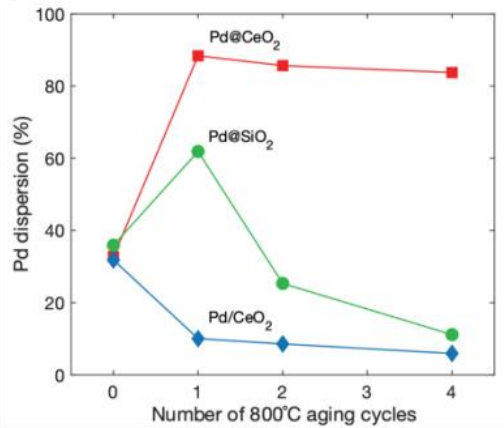

b)

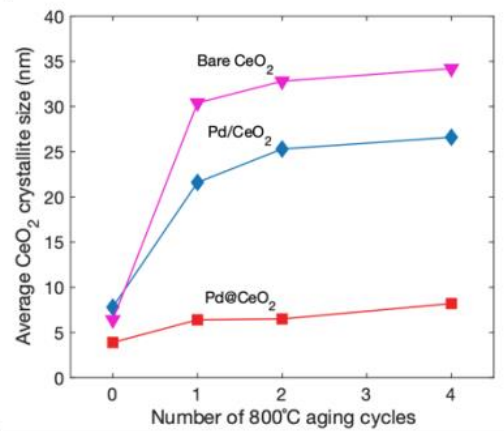

c)

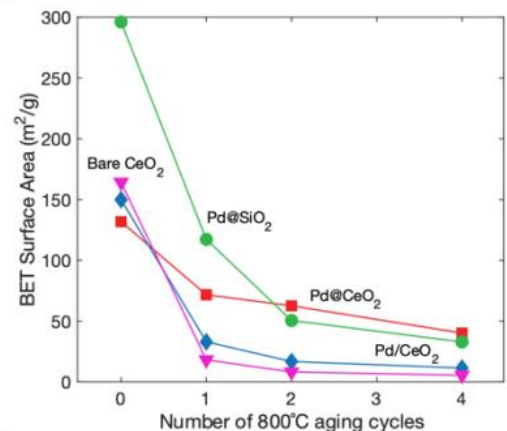

Figure 3. Changes in $\mathrm{Pd}$ dispersion, average $\mathrm{CeO}_{2}$ crystallite size, and BET surface area as a function of cycled aging. $\mathrm{Pd}$ dispersion as calculated from $\mathrm{CO}$ chemisorption for $\mathrm{Pd} / \mathrm{CeO}_{2}, \mathrm{Pd} @ \mathrm{SiO}_{2}$, and $\mathrm{Pd} @ \mathrm{CeO}_{2}$ catalysts as a function of the number of 4-hour $800^{\circ} \mathrm{C}$ aging cycles in air (a). Average $\mathrm{CeO}_{2}$ crystallite size as calculated by the Debye-Scherrer equation applied to XRD patterns of $\mathrm{Pd} / \mathrm{CeO}_{2}, \mathrm{Pd} @ \mathrm{CeO}_{2}$ and bare $\mathrm{CeO}_{2}$ nanospheres (b). BET surface area as determined by $\mathrm{N}_{2}$ physisorption (c).

$\mathrm{Pd}$ and $\mathrm{CeO}_{2}$ continued to agglomerate with successive aging cycles. By the end of the fourth $800^{\circ} \mathrm{C}$ aging cycle, the $\mathrm{Pd}$ dispersion dropped over five times to $5.9 \%$. This sintering is supported by XRD analysis in Figure S9, which shows a sharp peak corresponding to the (111) plane of bulk Pd. The $\mathrm{CeO}_{2}$ crystallite size increased over three times to $26.6 \mathrm{~nm}$, and the BET surface area had dropped around ten times to $11 \mathrm{~m}^{2} / \mathrm{g}$. Thus, the initial $800^{\circ} \mathrm{C}$ aging caused the most profound restructuring, with the relative magnitude of sintering dropping with each successive aging cycle. The continued sintering of $\mathrm{Pd} / \mathrm{CeO}_{2}$ resulted in a gradual increase in $\mathrm{T}_{90}$. Similar to the $\mathrm{Pd}$ dispersion loss and $\mathrm{CeO}_{2}$ domain growth trends, the $\mathrm{T}_{90}$ increase was more severe after the first aging cycle and plateaued over sequential cycles to a value of $210^{\circ} \mathrm{C}$. By the fourth exposure to $800^{\circ} \mathrm{C}$ aging conditions, $\mathrm{Pd} / \mathrm{CeO}_{2}$ had achieved a stable, albeit catalytically less active, structural state.

\section{Metastability of Halo Sites in Pd@ $\mathrm{SiO}_{2}$}

In contrast to the surface-impregnated $\mathrm{Pd} / \mathrm{CeO}_{2}$, the encapsulated $\mathrm{Pd} @ \mathrm{SiO}_{2}$ catalyst exhibited the formation of Pd halo sites, which increased dispersion from 35.9 to $61.9 \%$, after an initial $800^{\circ} \mathrm{C}$ aging (Figure 3, Table 1). Coinciding with the appearance of these sites was an increase in active metal utilization and a concurrent decrease in T90. The $\mathrm{Pd} @ \mathrm{SiO}_{2} \mathrm{catalyst}$ exhibited a $\mathrm{T}_{90}$ that decreased from 186 to $177^{\circ} \mathrm{C}$, corresponding to a decrease of $\sim 5 \%$. Due to the non-reducible nature of the supporting $\mathrm{SiO}_{2}$ shell, the improvements in Pd utilization and lowtemperature activity are attributed solely to redispersion increasing the availability of active metal sites for reaction. Recent work by Cargnello et al. demonstrated that whole particle migration and coalescence could exist as the dominant restructuring mechanism in $\mathrm{Pd} / \mathrm{SiO}_{2}$ catalysts during $800^{\circ} \mathrm{C}$ aging. ${ }^{37}$ In the core@shell system, however, we observe the coexistence of $\mathrm{Pd}$ cores alongside dispersed halo sites after the first cycle of aging. This suggests that total particle 
migration and coalescence is not the dominant restructuring mechanism in core@shell architectures. Several computational ${ }^{33,38}$ and experimental ${ }^{39-43}$ works suggest that the decomposition or disintegration of larger clusters into smaller mobile species can also occur in $800^{\circ} \mathrm{C}$ aging conditions. As such, it appears that encapsulation promotes active metal disintegration and transport, which is a process that is limited by the emission of mobile species. This may be due to steric effects imposed by the average pore size of the shell $(1.7 \mathrm{~nm})$ being twice as narrow as the initial core size $(3-5 \mathrm{~nm})$. To this end, we observed an aged $\mathrm{Pd} @ \mathrm{SiO}_{2}$ nanoparticle that contained redispersed Pd along with two Pd cores that had not sintered together (Figure S2). If particle migration was dominant in encapsulated morphologies, these two Pd cores would not exist as separate entities after high temperature aging. As such, this observation is consistent with the notion that encapsulation promotes active metal disintegration and redispersion, instead of total particle migration and coalescence, during high-temperature exposure. TEM investigation also identified some aged Pd cores that do not appear as unified nanoparticles as seen in the initial structures. Instead, these cores appear to have fragmented into many smaller Pd clusters, as seen in Figure S2. This observation also supports that Pd cores in encapsulated architectures do not migrate as single entities during high-temperature aging, but instead restructure through disintegration and emission. Consequently, it appears that encapsulation facilitates favorable restructuring by providing a physical barrier that promotes the emission-limited mobility of small metal species and inhibits local agglomeration through its porous, tortuous structure.

The existence of halo sites in $\mathrm{Pd} @ \mathrm{SiO}_{2}$ is short-lived, however. Cycled aging led to the eventual sintering of $\mathrm{Pd}$ in the $\mathrm{Pd} @ \mathrm{SiO}_{2}$ system after subsequent aging cycles. $\mathrm{Pd}$ dispersion dropped from $61.9 \%$ to $25.3 \%$ between the first and second $800^{\circ} \mathrm{C}$ aging cycle and proceeded to drop over five times to $11.1 \%$ by the fourth aging cycle. STEM analysis identified that the Pd did not remain within the encapsulating $\mathrm{SiO}_{2}$ envelope but had moved to the external surface of the supporting shell where it was locally sintered. The $\mathrm{Pd} @ \mathrm{SiO}_{2}$ catalyst also exhibited a significant loss in porosity over the four sequential aging cycles, as the surface area dropped from 296 to $32 \mathrm{~m}^{2} / \mathrm{g}$ (Figure 3, Table 1). These adverse morphological changes are reflected in the loss of catalytic activity. The $\mathrm{T}_{90}$ increased to $193^{\circ} \mathrm{C}$ and $197^{\circ} \mathrm{C}$ after the second and fourth cycles, respectively.

Our observation of initial dispersion and formation of halo sites, followed by sintering, suggests that the chemical interactions between the $\mathrm{Pd}$ metal and $\mathrm{SiO}_{2}$ support are insufficient to prevent mobile species from eventually agglomerating at high temperatures. On $\mathrm{SiO}_{2}$ supports, active metals are known to coordinate with silanol groups through dehydrogenation. ${ }^{44,45}$ As demonstrated in work by Guo et al., the interaction between dispersed metal and the $\mathrm{SiO}_{2} \mathrm{support}$ is relatively weak, as even mild temperature $\left(500^{\circ} \mathrm{C}\right)$ conditions can dislocate PGM from these isolated sites and induce local agglomeration into small, nanosized clusters. ${ }^{44}$ It appears that such a phenomenon occurs in $\mathrm{Pd} @ \mathrm{SiO}_{2}$ (Figure 1). As the concentration of silanol groups is strongly temperature-dependent, ${ }^{23}$ it is likely that repeated aging would decrease the number of trapping sites on the $\mathrm{SiO}_{2}$ support, which would increase the likelihood of sintering.

\section{Performance and Stability of Halo Sites in Pd@ $\mathrm{CeO}_{2}$}

Unlike the two catalysts discussed above, which exhibit degradation during hightemperature cycling, the catalytic performance of $\mathrm{Pd} @ \mathrm{CeO}_{2}$ obtained after the first aging was retained over four aging cycles (Figure 2, Table 1). EDS characterization confirmed that the first $800^{\circ} \mathrm{C}$ aging cycle redistributed core Pd into halo sites. These halo sites appear highly dispersed, 
as confirmed by electron microscopy and EDS analysis conducted at high magnification and resolution (Figure 5). These results are corroborated by $\mathrm{CO}$ chemisorption, which shows that dispersion increased by over two and a half times, from 32.8 to $88.4 \%$ (Figure 3, Table 1). Accompanying the improved utilization was a $\mathrm{T}_{90}$ that decreased from 153 to $103^{\circ} \mathrm{C}$. corresponding to a T90 decrease of $\sim 33 \%$, which is greater than that of aged $\mathrm{Pd} @ \mathrm{SiO}_{2}$.

The more uniform and complete redispersion of Pd observed after aging $\mathrm{Pd} @ \mathrm{CeO}_{2}$, compared to $\mathrm{Pd} @ \mathrm{SiO}_{2}$, suggests that the encapsulating $\mathrm{CeO}_{2}$ environment promotes the formation of highly dispersed halo sites. As both encapsulated catalysts have comparable initial core size and shell thickness, causes for the difference in redispersion appear to be related to the chemistry of the supporting material and the morphology of the encapsulating structure. Concerning chemical differences, $\mathrm{Pd}$ species have been shown to be trapped preferentially as single atoms on $\mathrm{Ce}^{3+}$ stepedges. ${ }^{33} \mathrm{Pd}$ cannot be stabilized in this highly dispersed fashion on $\mathrm{SiO}_{2}$ due to the weaker bonding between metal species and the $\mathrm{SiO}_{2}$ support. In addition, we previously demonstrated the reducibility of the $\mathrm{CeO}_{2}$ support was able to facilitate the oxidation and subsequent disintegration of core $\mathrm{Pd}$ to promote redispersion. ${ }^{16}$ Regarding morphological differences, the stacked crystallites of the $\mathrm{CeO}_{2}$ shell, which undergo dynamic restructuring simultaneously with the redispersing $\mathrm{Pd}$, may offer a larger resistance to outward transport of active metal. This would increase the likelihood of trapping on the $\mathrm{CeO}_{2}$ surface. Furthermore, the theoretical mean free path of gaseous $\mathrm{PdO}$ at $800^{\circ} \mathrm{C}$, which is on the order of $116 \mathrm{~nm}$, is significantly larger than the average pore diameter of the $\mathrm{CeO}_{2}$ shell, which is $1.5 \mathrm{~nm}$ (see Supporting Information for mean free path calculation details). Such considerations emphasize that encapsulation increases the likelihood that Pd species remain separated from one another and readily collide with the $\mathrm{CeO}_{2}$ surface to become trapped in highly dispersed arrangements during periods of thermally-induced transport.

While the greater redispersion plays a role in promoting activity and utilization, the reducible $\mathrm{CeO}_{2}$ environment should also be considered because catalytic turnover on reducible oxide supports is strongly dependent on the degree of interfacial contact between the active metal and the support. ${ }^{17}$ XPS analysis of the aged $\mathrm{Pd} @ \mathrm{CeO}_{2}$ catalyst conducted in our previous work identified that these halo sites exhibit $\mathrm{Pd}-\mathrm{O}-\mathrm{Ce}$ bonding. ${ }^{16}$ This is characteristic of dispersed $\mathrm{Pd}$ that bonds through an oxygen atom to undercoordinated $\mathrm{Ce}^{3+}$, which are typically located at step and edge sites on $\mathrm{CeO}_{2}$ crystals. ${ }^{33,46,47}$ As demonstrated in recent work by Wang et al., these Pd species adopt a coordination-unsaturated, square-planar structure. ${ }^{34}$ The formation of coordination-undersaturated $\mathrm{Pd}-\mathrm{O}-\mathrm{Ce}$ bonds perturb the local electronic environment of the $\mathrm{CeO}_{2}$, which improves lattice oxygen mobility and, subsequently, oxidative activity at low temperatures. ${ }^{34,48,49}$ XPS measurements in the $\mathrm{Pd} 3 \mathrm{~d}$ scan region of $\mathrm{Pd} @ \mathrm{CeO}_{2}$ and $\mathrm{Pd} / \mathrm{CeO}_{2}$ in their initial state, and after the first and fourth cycles of $800^{\circ} \mathrm{C}$ aging in air, were used to track the abundance of $\mathrm{Pd}-\mathrm{O}-\mathrm{Ce}$ during cycled aging. As shown in Figure 4, deconvolution of the XPS spectra showed a distribution of metallic $\mathrm{Pd}^{0}, \mathrm{Pd}^{2+}$ as $\mathrm{PdO}$ and $\mathrm{Pd}-\mathrm{O}-\mathrm{Ce}$ in the initial $\mathrm{Pd} / \mathrm{CeO}_{2}$ catalyst. The abundance of $\mathrm{Pd}-\mathrm{O}-\mathrm{Ce}$ increased slightly after the first aging cycle, which is consistent with notion that some $\mathrm{Pd}$ was redispersed on the surface of the $\mathrm{CeO}_{2}$ nanospheres during elevated temperature aging. The abundance of $\mathrm{Pd}-\mathrm{O}-\mathrm{Ce}$ appreciably decreased by the fourth aging cycle, however, giving rise to peak growth in regions characteristic of $\mathrm{Pd}^{0}$. This loss in $\mathrm{Pd}-\mathrm{O}-\mathrm{Ce}$ species likely contributes to the activity loss observed in aged $\mathrm{Pd} / \mathrm{CeO}_{2}$. The initial $\mathrm{Pd} @ \mathrm{CeO}_{2}$ sample was not subjected to deconvolution due to the low relative Pd signal obtained. This is likely due to screening from the encapsulating $\mathrm{CeO}_{2}$ shell. As $\mathrm{Pd}$ redisperses throughout the $\mathrm{CeO}_{2}$ shell during elevated temperature aging, the population of metal that exists within the photoelectron escape depth of the XPS instrument increases. ${ }^{16}$ This improves signal collection and permits 
deconvolution. Deconvolution identified $\mathrm{Pd}-\mathrm{O}-\mathrm{Ce}$ as the most abundant form of $\mathrm{Pd}$ on the aged $\mathrm{Pd} @ \mathrm{CeO}_{2}$ catalyst. The abundance of this type of oxidized Pd, which is known to promote facile oxygen transfer on $\mathrm{CeO}_{2}$ supports and oxidative activity, likely contributes to the superior performance of the catalyst.

a)

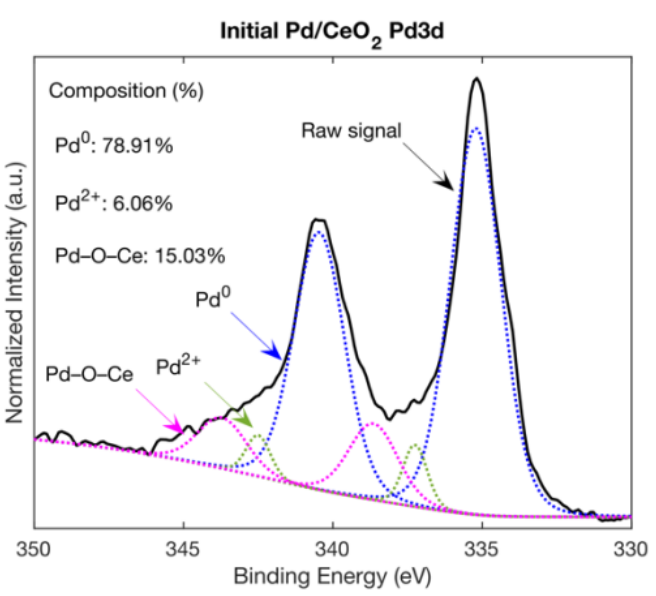

c)

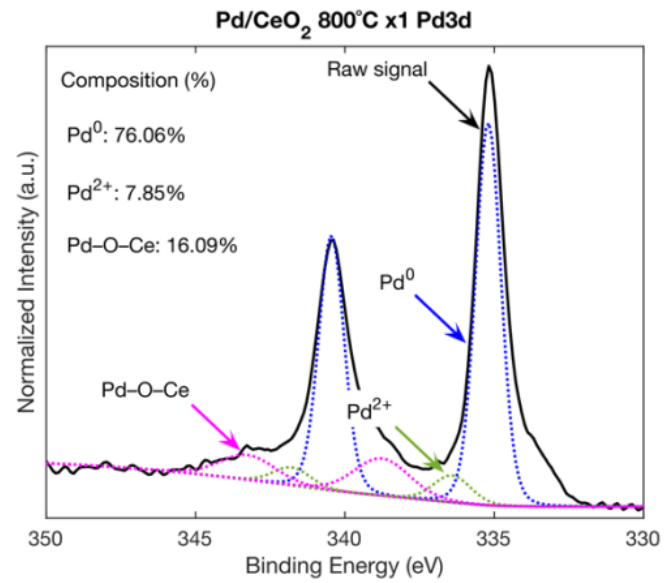

e)

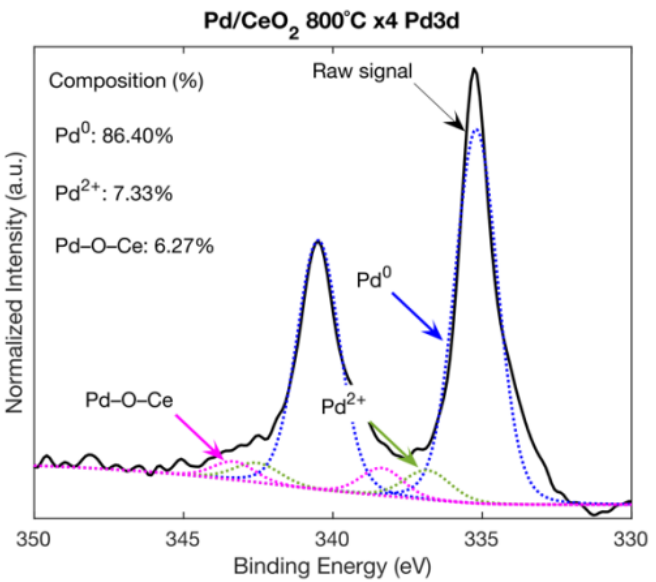

b)

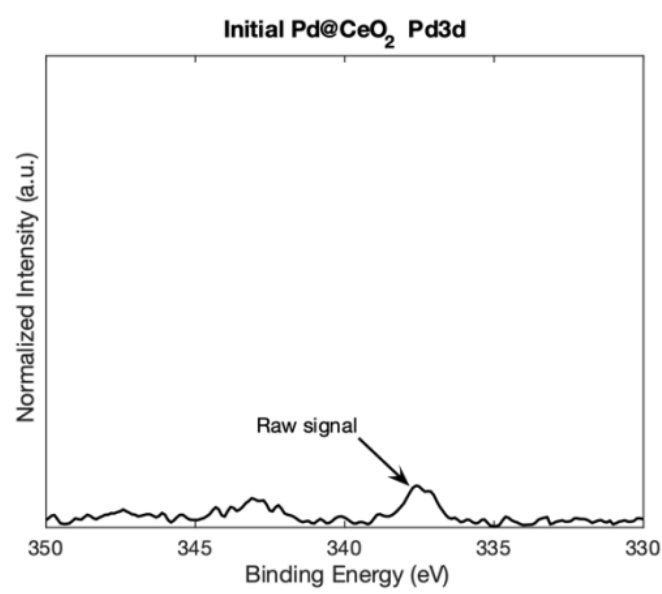

d)

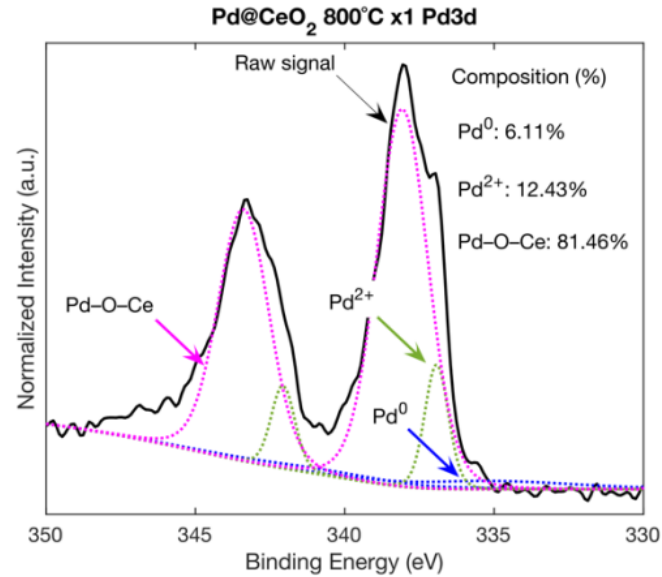

f)

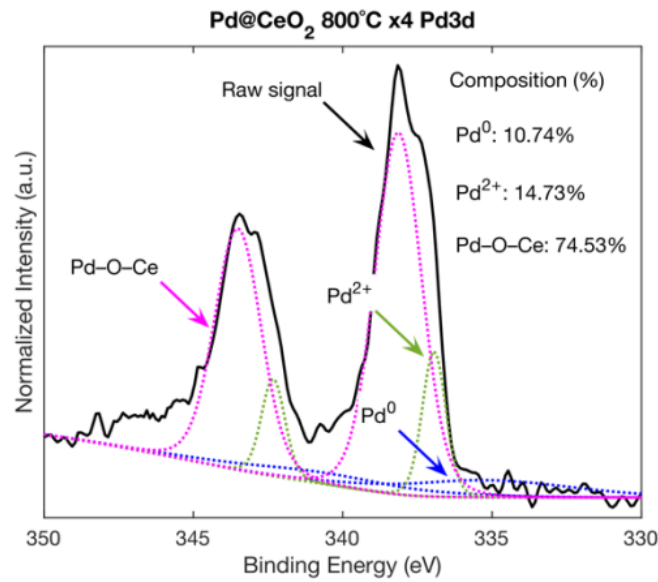

Figure 4. Effects of thermal aging on Pd oxidation state distribution. XPS spectra of the Pd3d scan region of $\mathrm{Pd} / \mathrm{CeO}_{2}$ and $\mathrm{Pd} @ \mathrm{CeO}_{2}$ in their initial state $(a, b)$ and after one ' $\mathrm{x} 1$ ' (c, d) and four ' $\mathrm{x} 4$ ' (e, f) repeated cycles of 4-hour $800^{\circ} \mathrm{C}$ aging in air. The relative percentage of each type of Pd, obtained through spectra deconvolution, have been inset. 
TGA experiments confirmed that the formation of halo sites improved the ease of abstracting oxygen from the $\mathrm{CeO}_{2}$ lattice, particularly at the low temperatures $\left(\leq 150^{\circ} \mathrm{C}\right)$ where aged $\mathrm{Pd} @ \mathrm{CeO}_{2}$ exhibits its superior catalytic performance (Figure S8). The total amount of oxygen released in $\mathrm{Pd} @ \mathrm{CeO}_{2}$ increased from 0.536 to $1.634 \mathrm{mmol} \mathrm{O}$ released $/ \mathrm{g}_{\mathrm{cat}}$ after aging. XPS analysis in the $\mathrm{O} 1 \mathrm{~s}$ scan region for $\mathrm{Pd} / \mathrm{CeO}_{2}$ and $\mathrm{Pd} @ \mathrm{CeO}_{2}$ after the first cycle of $800^{\circ} \mathrm{C}$ air aging was also conducted to examine how thermally-induced restructuring affected the distribution of oxygen species on the catalyst (see Methods Section and Figure S10 for O1s XPS analysis). Deconvolution on the obtained spectra indicated that both catalysts exhibit varying abundances of three types of oxygen: $\mathrm{O}_{\mathrm{I}}$, which is associated with bulk oxygen in the $\mathrm{CeO}_{2}$ lattice, ${ }^{50,51} \mathrm{O}_{\text {III }}$, which is associated with surface bound oxygen species and/or oxygen vacancies, ${ }^{51,52}$ and $\mathrm{O}_{\text {III }}$, which is associated with hydroxyl groups or $\mathrm{H}_{2} \mathrm{O}$ bound to the surface of $\mathrm{CeO}_{2}{ }^{53} \mathrm{O}_{\mathrm{II}}$, which has been discussed in literature as being particularly mobile on $\mathrm{CeO}_{2}$ supports and thus contributing to improved oxidative activity, is over 1.5 times more abundant in $\mathrm{Pd} @ \mathrm{CeO}_{2}$ than $\mathrm{Pd} / \mathrm{CeO}_{2}$ after the first cycle of aging. As such, it is likely that the superior Pd redispersion and greater access to lattice oxygen are working synergistically here to improve catalytic performance. It should be noted that this type of bonding has been leveraged to improve activity on metal oxide supports beyond $\mathrm{CeO}_{2}$, such as $\mathrm{TiO}_{2} .{ }^{54}$

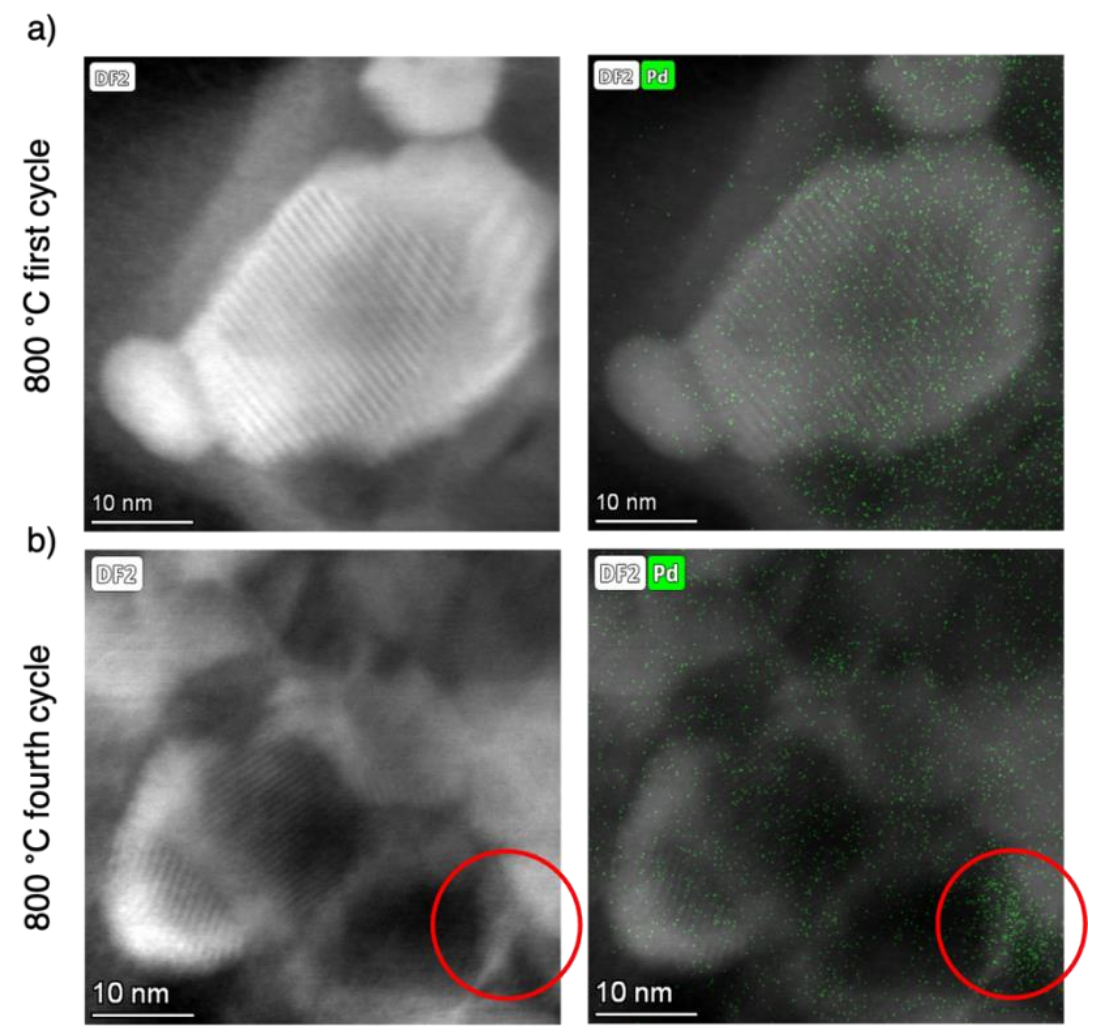

Figure 5. Examining Pd distribution in aged $\mathrm{Pd} @ \mathrm{CeO}_{2}$. High-resolution TEM and overlaid EDS elemental mapping of $\mathrm{Pd} @ \mathrm{CeO}_{2}$ catalysts after one (a) and four (b) repeated cycles of 4-hour $800^{\circ} \mathrm{C}$ aging in air. Embedded legends on each Figure indicate the corresponding colors for the elemental maps (Pd: Green) and the detector used to collect the STEM image (DF: Dark-field). Red circles highlight grain boundaries between multiple restructured $\mathrm{CeO}_{2}$ crystallites, where Pd appears to have localized after sequential aging.

Cycled aging of $\mathrm{Pd} @ \mathrm{CeO}_{2}$ resulted in slight $\mathrm{CeO}_{2}$ support growth and Pd dispersion loss. The slight loss of Pd dispersion was reflected in XPS experiments as the abundance of $\mathrm{Pd}-\mathrm{O}-\mathrm{Ce}$ was seen to drop from 81.46 to $74.53 \%$ between the first and fourth cycles of $800^{\circ} \mathrm{C}$ aging. 
However, these effects were significantly smaller than in the other catalysts and did not readily affect catalytic performance as the low $\mathrm{T}_{90}$ obtained after the first aging was retained after four aging cycles (Figure 2, Table 1). $\mathrm{Pd} @ \mathrm{CeO}_{2}$ also exhibited the greatest surface area $\left(40 \mathrm{~m}^{2} / \mathrm{g}\right.$ ) among all catalysts subjected to the four aging cycles, which further demonstrates the relative stability of the structure. The most apparent structural change as result of cycled aging is the that the supporting domains between $\mathrm{Pd} @ \mathrm{CeO}_{2}$ particles had grown together during high-temperature aging. XRD analysis shows that the $\mathrm{CeO}_{2}$ domains grow, albeit slightly, from $\sim 4 \mathrm{~nm}$ to $\sim 8 \mathrm{~nm}$ by the fourth aging cycle. This slight rearrangement and growth may be responsible for the observed localizing of halo sites at $\mathrm{CeO}_{2}$ grain boundaries, as shown in Figure 5 and $\mathrm{S} 4$. This localizing, however, did not significantly impact the Pd dispersion, as it dropped only slightly from 88.4 to $83.7 \%$. CO chemisorption and light-off experiments also confirm that the crystallite growth did not adversely affect gas-phase accessibility to active sites.

Overall, the robust catalytic performance of $\mathrm{Pd} @ \mathrm{CeO}_{2}$ can be attributed to the ability of the support to effectively trap $\mathrm{Pd}$ and the synergistic slowing down of $\mathrm{CeO}_{2}$ grain growth. The $\mathrm{CeO}_{2}$ crystallites that form the encapsulating shell are favorable for facilitating active metal trapping. They exhibit a high abundance of step and edge sites relative to their volume (Figure 1, S3), containing undercoordinated $\mathrm{Ce}^{3+}$ that can readily form strong chemical bonds with mobile PGM species. ${ }^{11,55}$ Furthermore, comparison with the adverse growth of both $\mathrm{Pd}$ and $\mathrm{CeO}_{2}$ domains on conventional $\mathrm{Pd} / \mathrm{CeO}_{2}$ demonstrates that the stabilization of supporting crystallites scales with the degree of metal redispersion. This demonstrates the importance of encapsulated morphologies for directing the formation of abundant and highly dispersed halo sites that can effectively stabilize support morphology. Such observations are consistent with previous works, which show that M$\mathrm{O}-\mathrm{Ce}$ bonding (where $\mathrm{M}$ is a $\mathrm{PGM}$ ) on $\mathrm{CeO}_{2}$ slows sintering and support collapse. ${ }^{32,34,56} \mathrm{~A}$ number of computational studies demonstrate the stability of $\mathrm{Pd}$ trapped on $\mathrm{CeO}_{2}$ surfaces. ${ }^{46,57-59}$ It is the strength of these interactions and the physical intercalation of metal species that likely stabilizes the Pd halo sites, as well as the supporting $\mathrm{CeO}_{2}$ domains. A schematic interpretation of the formation and stability of $\mathrm{Pd}$ halo sites in $\mathrm{Pd} @ \mathrm{SiO}_{2}$ and $\mathrm{Pd} @ \mathrm{CeO}_{2}$ is presented in Scheme 2 to summarize these findings. The consistent performance and structural stability of aged $\mathrm{Pd} @ \mathrm{CeO}_{2}$ experimentally validate how precise tuning of support morphology and chemistry can improve material utilization and robustness in high-temperature conditions. 
a)
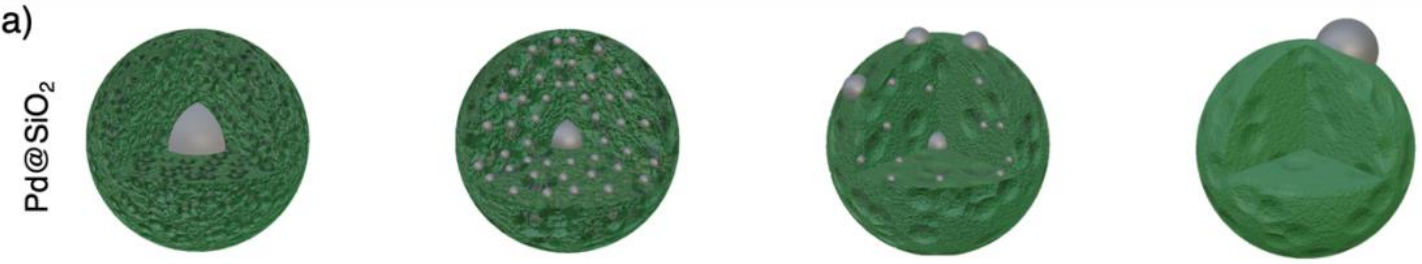

- Pd redisperses into halo sites

- Halo sites migrate during cycled aging

- Halo sites sinter and pores collapse

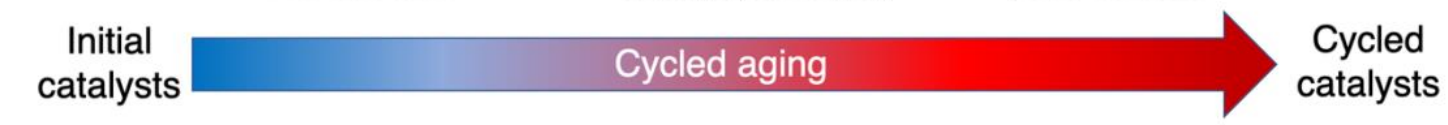

b)

- Pd redisperses
into halo sites

- Halo sites stabilize
$\mathrm{CeO}_{2}$ crystallites

- Structure maintains superior stability and activity
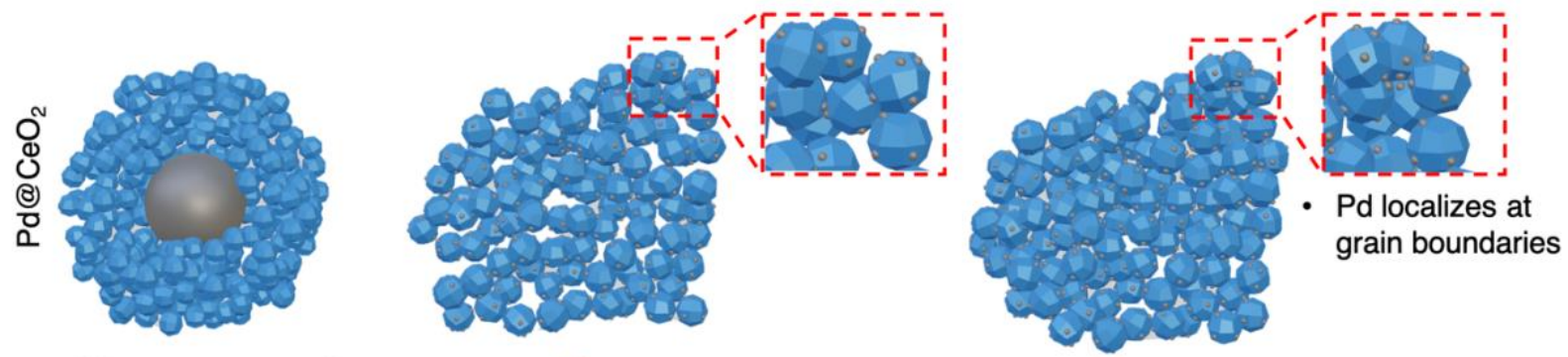

Palladium

$\mathrm{SiO}_{2}$ shell

$\mathrm{CeO}_{2}$ crystallite

Scheme 2. Graphical depiction of the restructuring of $\mathrm{Pd} @ \mathrm{SiO}_{2}$ (a) and $\mathrm{Pd} @ \mathrm{CeO}_{2}$ (b) catalysts as a function of repeated exposure to $800^{\circ} \mathrm{C}$ aging conditions.

\section{Understanding the role of support reducibility in halo site stability}

The reducibility of the $\mathrm{CeO}_{2}$ shell support dramatically improves both catalytic performance and stability through the formation of strong metal-support interactions. ${ }^{24,49,60}$ As such, we sought to better understand the role of support reducibility in promoting the stability of dispersed Pd species. To achieve this, we aged the $\mathrm{Pd} @ \mathrm{CeO}_{2}$ catalyst, after forming halo sites through $800^{\circ} \mathrm{C}$ air aging, in a completely reduced state, as shown in Figure 5. Complete reduction of the catalyst was performed by cutting the flow of gaseous $\mathrm{O}_{2}$ in the presence of $1 \% \mathrm{CO}$ and $\mathrm{N}_{2}$, as demonstrated in previous work (see Methods Section and Figure S11-S12 for reduced aging protocols, corresponding light-off plots and STEM/EDS characterization).${ }^{16}$ For conciseness, we refer to this aging protocol as 'reduced' aging. 


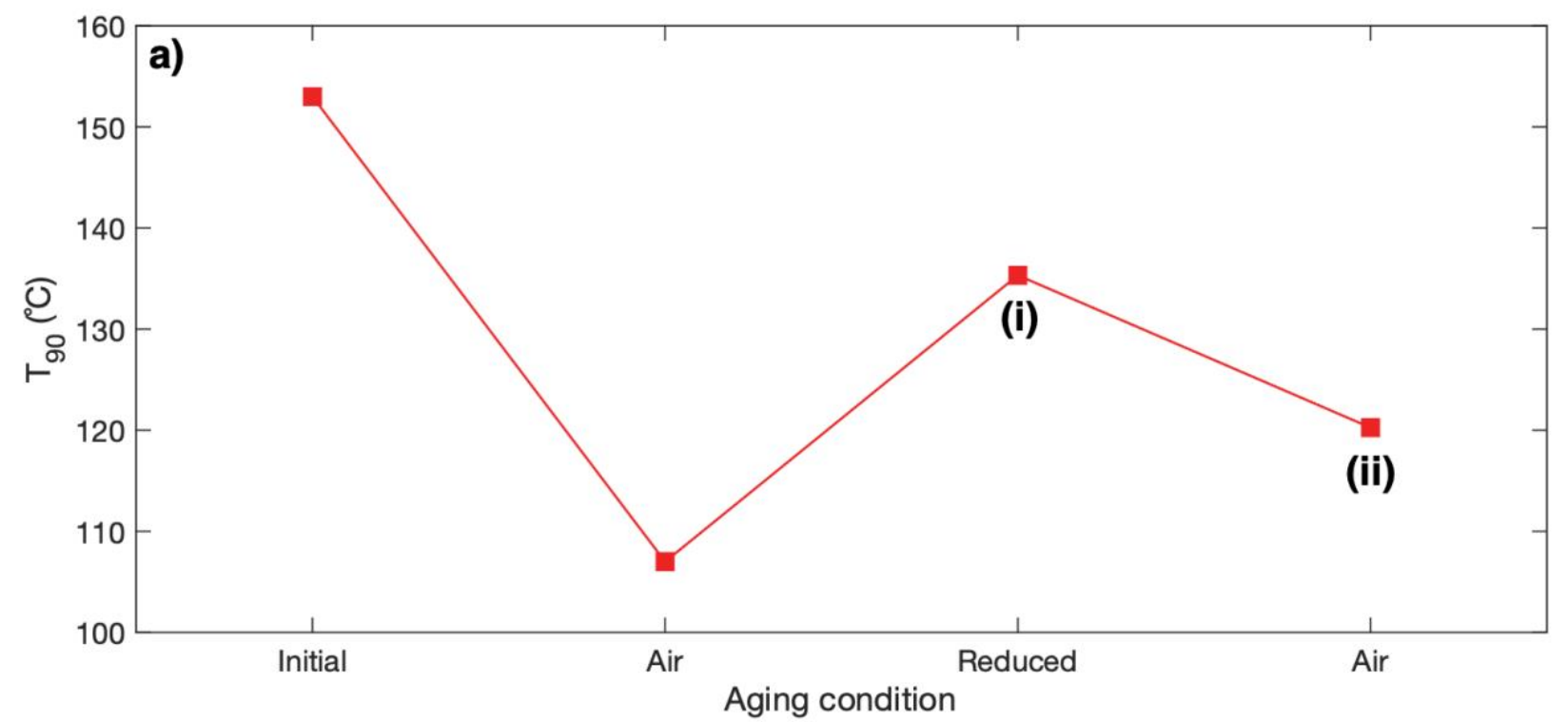

Reduced aging
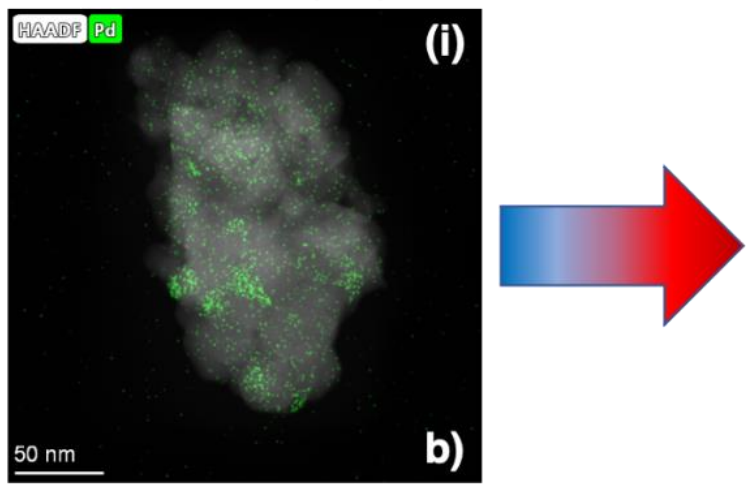

Subsequent air aging

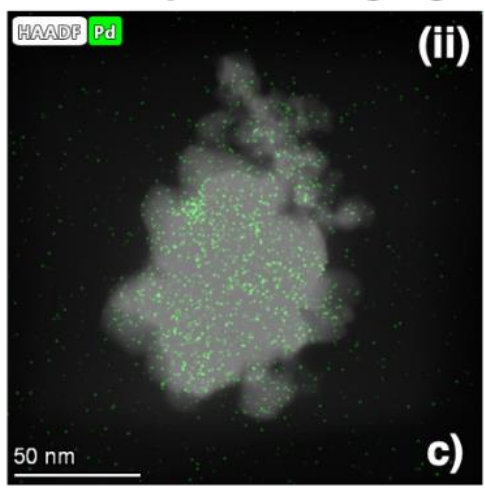

Figure 5. Influence of aging in a reduced environment on $\mathrm{Pd} @ \mathrm{CeO}_{2}$ structure and activity. $\mathrm{T}_{90}$ for $\mathrm{CO}$ oxidation for $\mathrm{Pd} @ \mathrm{CeO}_{2}$, which has been subsequently aged in air (Air aging), then reduced under the flow of excess $\mathrm{CO}$ and aged at $800^{\circ} \mathrm{C}$ in pure $\mathrm{N}_{2}$ (Reduced aging), and then subsequently aged again in air at $800^{\circ} \mathrm{C}$ (a). STEM analysis with overlaid EDS elemental mapping of the latter two aging cycles have been included to elucidate trends in Pd dispersion $(b, c)$. These microscopy images have been labelled as (i) and (ii) respectively, to indicate which data points they correspond to in Figure 5a.

The bonding of dispersed active metal species that exhibit $\mathrm{M}-\mathrm{O}-\mathrm{Ce}$ coordination is mediated through atomic oxygen. ${ }^{61-63}$ As such, it is expected that conditions which perturb the stability of that oxygen species would dislocate trapped active metal. Consistent with this expectation, reduced aging at $800^{\circ} \mathrm{C}$ appeared to affect halo site stability adversely. EDS analysis identified some Pd species that seemed to remain dispersed. However, several Pd agglomerates, some on the order of $\sim 25 \mathrm{~nm}$ in diameter, were also observed. The loss of some halo sites also appeared to affect the stability of polycrystalline $\mathrm{CeO}_{2}$, as grains larger than those obtained after four cycles of $800^{\circ} \mathrm{C}$ aging in air were seen under STEM inspection. Coinciding with this adverse restructuring was a $\mathrm{T}_{90}$ for $\mathrm{CO}$ oxidation that increased from 103 to $135^{\circ} \mathrm{C}$. This finding builds upon our previous work, which showed that the reducibility of $\mathrm{CeO}_{2}$ could promote $\mathrm{Pd}$ redispersion, ${ }^{16}$ by demonstrating that the oxidation state of $\mathrm{CeO}_{2}$ helps stabilize halo sites during high-temperature exposure. Kim et al. showed that subjecting catalysts with appreciable $\mathrm{Pt}-\mathrm{O}-\mathrm{Ce}$ 
sites to reducing conditions can remove some of the oxygen species that promote anchoring, adversely affecting the structural stability. ${ }^{56}$ Our findings from the reduced aging of $\mathrm{Pd} @ \mathrm{CeO}_{2}$, which are consistent with this past literature, support the conclusion that the stability of atomic oxygen, which mediates the interaction between dispersed active metal and metal oxide supports, directly affects the overall stability of Pd halo sites.

The $\mathrm{T}_{90}$ value of the reduced aged $\mathrm{Pd} @ \mathrm{CeO}_{2}\left(135^{\circ} \mathrm{C}\right)$ is lower than that of the initial $\mathrm{Pd} @ \mathrm{CeO}_{2}$, likely due to the partial retention of highly dispersed halo sites as confirmed by EDS analysis. This $\mathrm{T}_{90}$ value is also lower than that of a $\mathrm{Pd} @ \mathrm{CeO}_{2}$ catalyst that has been subjected to reduced aging prior to the $800^{\circ} \mathrm{C}$ air aging protocol that forms halo sites $\left(186^{\circ} \mathrm{C}\right.$, see Figure S13-S15 for corresponding aging protocols, light-off plots and STEM/EDS characterization). These observations suggest that $\mathrm{Pd}$ halo sites exhibit greater resistance to adverse restructuring under highly reducing, elevated temperature conditions than as-prepared $\mathrm{Pd}$ species. The Pt species in the study conducted by Kim et al. exhibited improved stability to the adverse reduction that promotes metal dislocation and sintering due to the strong $\mathrm{Pt}-\mathrm{O}-\mathrm{Ce}$ bonding that forms after $800^{\circ} \mathrm{C}$ exposure. ${ }^{56} \mathrm{As}$ such, the abundance of $\mathrm{Pd}-\mathrm{O}-\mathrm{Ce}$ bonding likely contributes to the improved stability of halo sites under high-temperature reducing conditions.

To examine the role of catalyst oxidation for promoting favorable restructuring, we aged the partially deactivated, reduced $\mathrm{Pd} @ \mathrm{CeO}_{2}$ back in air at $800^{\circ} \mathrm{C}$ for 4 hours. As shown in Figure 5, returning to these aging conditions recovered a portion of the low-temperature catalytic performance as the T90 decreased from 135 to $120^{\circ} \mathrm{C}$. EDS analysis identified a greater abundance of dispersed Pd halo sites, which is likely the cause for the improved T90. While some larger $\mathrm{Pd}$ agglomerates persisted, our observations demonstrate that aging at $800^{\circ} \mathrm{C}$ in air can regenerate a portion of the Pd halo sites that have sintered. Our findings agree with other works that have emphasized the importance of controlling redox conditions for directing the restructuring behavior of Pd. ${ }^{41,64}$

\section{CONCLUSIONS}

In this work, we sought to understand the formation, activity, and structural stability of nanoscale Pd halo sites formed by exposing core@shell catalysts repeatedly to the hightemperature conditions commonly encountered in industrial applications. While encapsulation improves metal utilization and activity through the formation of halo sites, our cycled aging experiments indicate that these sites cannot be maintained in all catalysts. The weak bonding between $\mathrm{Pd}$ and $\mathrm{SiO}_{2}$ makes halo sites in $\mathrm{Pd} @ \mathrm{SiO}_{2}$ susceptible to continued $\mathrm{Pd}$ transport and ultimately sintering. In contrast, the formation of halo sites improves structural stability in $\mathrm{Pd} @ \mathrm{CeO}_{2}$, likely due to the $\mathrm{Pd}-\mathrm{O}-\mathrm{Ce}$ bonding that forms between the $\mathrm{CeO}_{2}$ support and dispersed $\mathrm{Pd}$. In stabilizing step and edge sites on the $\mathrm{CeO}_{2}$ lattice, halo sites were found to mitigate the adverse sintering and structural collapse of support domains during cycled high-temperature aging. The retention of the $\mathrm{Pd} @ \mathrm{CeO}_{2}$ catalyst's superior low-temperature performance between the first and fourth aging cycles emphasizes that favorable restructuring in core@shell architectures can significantly improve catalytic lifetime. By subjecting the $\mathrm{Pd} @ \mathrm{CeO}_{2}$ catalyst to reduced aging, we further demonstrate that the oxidation state of the support is integral to stabilizing high dispersions of the active metal. Returning to air aging conditions can regenerate a portion of highly dispersed species from larger agglomerates, which delineates a simple methodology for recovering dispersion and activity on-stream. By examining the stability of highly active halo sites in core@shell architectures, we demonstrate how the initial catalyst can be designed to promote 
favorable high-temperature nanoscale restructuring that improves catalytic performance, stability, and material utilization.

\section{METHODS}

Synthesis of Surface-Impregnated (Conventionally Supported) $\mathrm{Pd} / \mathrm{CeO}_{2}$

Surface-impregnated $\mathrm{Pd} / \mathrm{CeO}_{2}$ catalysts were prepared by wet impregnating $\mathrm{Pd}$ onto already synthesized $\mathrm{CeO}_{2}$ nanospheres (NS).

$\mathrm{CeO}_{2} \mathrm{NS}$ were made by adding a $0.0564 \mathrm{mM}$ solution of acetic acid $\left(\mathrm{CH}_{3} \mathrm{COOH}, 99.7 \%\right.$, Sigma Aldrich) in anhydrous ethylene glycol $\left(\left(\mathrm{CH}_{2} \mathrm{OH}\right)_{2}, 99.8 \%\right.$, Sigma Aldrich) to a $2.30 \mathrm{M}$ aqueous solution of cerium nitrate hexahydrate $\left(\mathrm{Ce}\left(\mathrm{NO}_{3}\right)_{3} \cdot 6 \mathrm{H}_{2} \mathrm{O}, 99 \%\right.$, Sigma Aldrich) under vigorous stirring. The solution was sealed in an autoclave and heated at $180^{\circ} \mathrm{C}$ for 4 hours.

After washing and drying, the $\mathrm{CeO}_{2} \mathrm{NS}$ were made into a $64.6 \mathrm{mM}$ aqueous dispersion in deionized water (DI $\mathrm{H}_{2} \mathrm{O}$ ) and left to stir. A $7.51 \mathrm{mM}$ aqueous solution of palladium nitrate dihydride $\left(\mathrm{Pd}\left(\mathrm{NO}_{3}\right)_{2} \cdot 2 \mathrm{H}_{2} \mathrm{O}, 99 \%\right.$ Sigma Aldrich) in $\mathrm{DI}_{2} \mathrm{O}$ was added to the $\mathrm{CeO}_{2} \mathrm{NS}$ mixture under vigorous stirring and left to stir for 12 hours. Once the stirring had completed, the solution was dried in an oven at $110^{\circ} \mathrm{C}$. The catalysts were then aged in a muffle furnace at $500^{\circ} \mathrm{C}$ in air for 2 hours. At this stage, the catalyst was considered in its initial state. All initial catalysts were subjected to characterization by transmission electron microscopy and x-ray energy dispersive spectroscopy prior to catalytic testing. After initial characterization to confirm morphology, synthesized samples were split into two batches: one set to be used for catalytic testing and subjected to in-situ aging and another set for ex-situ aging and material characterization.

\section{Synthesis of Core@shell Catalysts}

All synthesized core@ shell catalysts were subjected to hydrothermal aging at $80^{\circ} \mathrm{C}$ for 4 hours. After the hydrothermal aging, the core@shell catalysts were collected by centrifugation and washed three times with water and three times with ethanol. The catalysts were then aged in a muffle furnace at $500^{\circ} \mathrm{C}$ in air for 2 hours. At this stage, the catalyst was considered in its initial state. All initial catalysts were subjected to characterization by transmission electron microscopy and x-ray energy dispersive spectroscopy prior to catalytic testing. After initial characterization to confirm morphology, synthesized samples were split into two batches: one set to be used for catalytic testing and subjected to in-situ aging and another set for ex-situ aging and material characterization.

\section{Synthesis of Pd@CeO Catalysts}

$\mathrm{Pd} @ \mathrm{CeO}_{2}$ core@shell nanoparticles were prepared using a previously reported one-pot methodology of a base-catalyzed polymerization of a $\mathrm{CeO}_{2}$ precursor around formed $\mathrm{Pd}$ nanoparticle seeds. ${ }^{16,25}$ However, in this work we improved upon the method by periodically adjusting the $\mathrm{pH}$ during the synthesis to maintain alkaline conditions. This was inspired by recent work, which demonstrated that the synthesis $\mathrm{pH}$ plays a critical role in mediating the crystallinity and stability of encapsulating metal oxide structures. ${ }^{65,66}$

A solution of $5.95 \mathrm{mM}$ trimethyl tetradecyl ammonium bromide (TTAB, 99\% Sigma Aldrich) in $\mathrm{DI} \mathrm{H}_{2} \mathrm{O}$ was made and left under vigorous stirring. Pd nanoparticles were made from a $15.8 \mathrm{mM}$ solution in $\mathrm{DI} \mathrm{H}_{2} \mathrm{O}$. The solution was added to the TTAB solution. A $1.02 \mathrm{M}$ aqueous hydrazine hydrate $\left(\mathrm{N}_{2} \mathrm{H}_{4} \bullet \mathrm{H}_{2} \mathrm{O}, 99 \%\right.$ Sigma Aldrich) solution was added shortly after to reduce the ionic dissolution $\mathrm{Pd}^{2+}$ to $\mathrm{Pd}$ nanoparticles, which act as the core seeds. 
Once reduced, a solution of $5.20 \mathrm{mM}$ TTAB in $\mathrm{DI} \mathrm{H} \mathrm{H}_{2} \mathrm{O}$ was added to disperse the Pd further and facilitate encapsulation of core seeds into discrete core@shell nanoparticles. The $\mathrm{pH}$ of the solution was adjusted to 10.7 using aqueous sodium hydroxide ( $\mathrm{NaOH}, 99 \%$ Sigma Aldrich), and the solution was left uncovered to stir vigorously for 30 minutes. Cerium-isobutyrate (Ce-iso) was made into a $52.2 \mathrm{mM}$ solution with ethanol. Ce-iso was prepared prior to synthesis according to the previously reported procedure. $13.6 \mathrm{mmol}$ of triethanolamine (TEA, 99\% Sigma Aldrich) was added dropwise to the Ce-iso solution to form cerium atrane (Ce-at).

After 30 minutes, the $\mathrm{pH}$ of the system was readjusted to 10.7, and the Ce-at solution was added dropwise. The solution was then left covered to stir for 24 hours vigorously. After stirring, the solution was transferred to an oven for hydrothermal aging.

\section{Synthesis of Pd@SiO $\mathrm{Satalysts}_{2}$}

Similar to the synthesis of $\mathrm{Pd} @ \mathrm{CeO}_{2}$, a $30 \mathrm{mM}$ aqueous solution of $\mathrm{Pd}\left(\mathrm{NO}_{3}\right)_{2} \cdot 2 \mathrm{H}_{2} \mathrm{O}$ was added to a $10 \mathrm{mM}$ aqueous TTAB solution and reduced with $1.02 \mathrm{M}$ aqueous $\mathrm{N}_{2} \mathrm{H}_{4} \cdot \mathrm{H}_{2} \mathrm{O}$ solution while under vigorous stirring. The solution was left to stir for 30 minutes (to allow for completed decomposition of $\mathrm{N}_{2} \mathrm{H}_{4} \bullet \mathrm{H}_{2} \mathrm{O}$ ) after the $\mathrm{pH}$ of the solution was adjusted to 10.7 with aqueous $\mathrm{NaOH}$.

The $\mathrm{pH}$ was readjusted to 10.7 after the 30 -minute period, and $5 \mathrm{~mL}$ of a $5.71 \mathrm{mM}$ tetraethylorthosilicate (99\%, Sigma Aldrich, TEOS) in ethanol solution was added dropwise. The solution was left to stir for 24 hours prior to hydrothermal aging.

\section{Aging Parameters}

For the purposes of this study, in-situ aging refers to aging in the catalytic test bed for analyzing the effects of aging on catalytic performance, and ex-situ aging refers to aging conducted in a temperature programmable furnace for examining morphology and structural changes due to aging.

\section{In-situ Aging to Examine Changes in Catalytic Activity}

Upon completing an initial light-off test (see below for light-off test reaction conditions), catalysts were left to cool to ambient conditions under the flow of dry air at $200 \mathrm{~mL} / \mathrm{min}$. Once cooled, the catalysts were heated to $800^{\circ} \mathrm{C}$ with a ramp of $5^{\circ} \mathrm{C} / \mathrm{min}$ under flowing air at 200 $\mathrm{mL} / \mathrm{min}$. Finally, the catalysts were held at $800^{\circ} \mathrm{C}$ for 4 hours. This defined one cycle of $800^{\circ} \mathrm{C}$ aging. Once the 4-hour aging period had finished, the catalysts were cooled to $35^{\circ} \mathrm{C}$, and the flowing gas was changed from air to the test gas (see below for test gas information). This cycled aging and light-off testing was repeated until four cycles of $800^{\circ} \mathrm{C}$ aging had been conducted.

\section{Ex-situ Aging to Examine Changes in Catalyst Structure and Morphology}

Catalyst samples were placed in a tube furnace and heated to $800^{\circ} \mathrm{C}$ with a ramp of $5^{\circ} \mathrm{C} / \mathrm{min}$ under flowing air at $200 \mathrm{~mL} / \mathrm{min}$. The catalysts were held at $800^{\circ} \mathrm{C}$ for 4 hours. This process defined one cycle of $800^{\circ} \mathrm{C}$ aging. Once the 4-hour aging period had finished, the catalysts were cooled to ambient temperature, removed from the tube furnace, and subjected to characterization (see below for more information). This cycled aging and characterization was repeated until four cycles of $800^{\circ} \mathrm{C}$ aging had been conducted.

\section{In-situ Reduced Aging of $\mathrm{Pd} @ \mathrm{CeO}_{2}$}

Two sets of initial $\mathrm{Pd} @ \mathrm{CeO}_{2}$ catalyst were subjected to aging while the supporting ceria was reduced to examine the role of support reducibility in facilitating Pd mobility and trapping. 
Reduction of the $\mathrm{Pd} @ \mathrm{CeO}_{2}$ catalyst was conducted at $300^{\circ} \mathrm{C}$ after the conclusion of a light-off test to maintain $100 \%$ conversion of $\mathrm{CO}$. The flow of gas-phase $\mathrm{O}_{2}$ was cut, and the catalyst was exposed to flowing $1 \% \mathrm{CO}$ in an $\mathrm{N}_{2}$ gas balance for 15 minutes. The $\mathrm{CO}$ conversion, which was monitored by downstream FTIR, was confirmed to drop to zero over this timeframe, which indicated the complete reduction of the ceria support. This $\mathrm{O}_{2}$-cut approach was described in our previous work. ${ }^{16}$ Once the support was reduced, the flow of $\mathrm{CO}$ was cut, and the $\mathrm{Pd} @ \mathrm{CeO}_{2}$ was aged at $800^{\circ} \mathrm{C}$ for 4 hours in pure $\mathrm{N}_{2}$ flowing at $200 \mathrm{~mL} / \mathrm{min}$ to ensure the support would not reoxidize. Once the 4-hour aging period had finished, the catalysts were cooled to ambient temperature and exposed to $2.5 \% \mathrm{O}_{2}$ with an $\mathrm{N}_{2}$ gas balance, flowing at $200 \mathrm{~mL} / \mathrm{min}$ for 2 hours prior to light-off testing to ensure re-oxidation of the support. One set of $\mathrm{Pd} @ \mathrm{CeO}_{2}$ was subjected to this $\mathrm{N}_{2}$ aging after an initial light-off test, and another set of $\mathrm{Pd} @ \mathrm{CeO}_{2}$ was subjected to $\mathrm{N}_{2}$ aging after being aged in-situ under the flow of air at $800^{\circ} \mathrm{C}$ for 4 hours.

\section{Reaction Conditions}

$\mathrm{CO}$ oxidation light-off tests were used to examine catalytic activity. Catalytic tests were conducted in a $4.00 \mathrm{~mm}$ internal diameter quartz reactor tube, encapsulated in a temperature programmable furnace, subjected to continuous gas flow. This system defines the catalytic testbed. Samples were heated to $500^{\circ} \mathrm{C}$ (achieved with a ramp of $5^{\circ} \mathrm{C} / \mathrm{min}$ ) under flowing $2.5 \% \mathrm{O}_{2}$ with an $\mathrm{N}_{2}$ balance for 1.5 hours prior to initial catalytic testing to clean the catalyst surface. The test gas was comprised of $1 \% \mathrm{CO}$ and $2.5 \% \mathrm{O}_{2}$ with an $\mathrm{N}_{2}$ gas balance. The total gas flow rate was set to $200 \mathrm{~mL} / \mathrm{min}$. $60 \mathrm{mg}$ of catalyst (which was sieved to $60-80 \mathrm{mesh}$ ) was diluted with $100 \mathrm{mg}$ of $\mathrm{SiO}_{2}$ (also sieved to $60-80$ mesh) to mitigate the formation of hot spots in the catalyst bed during light-off testing.

For light-off tests, the encapsulating furnace temperature was raised from $50^{\circ} \mathrm{C}$ to $300^{\circ} \mathrm{C}$, achieved by a $2^{\circ} \mathrm{C} / \mathrm{min}$ ramp to ensure good linear temperature control and proper heat transfer. The reactor was connected to a downstream FTIR analyzer, which was used to provide real-time quantification of the effluent gas components. Catalysts were subjected to a variety of in-situ aging in the testbed after initial testing.

\section{Measuring Conversion of $\mathrm{CO}$}

The conversion of $\mathrm{CO}$, which was used to identify $\mathrm{T}_{90}$ and plot the light off profiles, was calculated as follows:

$$
X_{C O}[\%]=\left(\frac{[C O]_{\text {in }}-[C O]_{\text {out }}}{[C O]_{\text {in }}}\right) \times 100[\%]
$$

where $X_{C O}$ is the conversion of $\mathrm{CO}$ and $[\mathrm{CO}]_{\text {in }}$ and $[\mathrm{CO}]_{\text {out }}$ are the concentrations of $\mathrm{CO}$ in the inlet and outlet gas streams, respectively.

\section{Rate of CO Conversion to Probe Pd Utilization}

The rate of $\mathrm{CO}_{2}$ production at $40^{\circ} \mathrm{C}$, normalized by the mass content of $\mathrm{Pd}$ within each catalyst, was used to probe active metal utilization prior to and post $800^{\circ} \mathrm{C}$ aging. $40^{\circ} \mathrm{C}$ was used for the experiment to ensure a completely kinetic regime. During each experiment, the conversion of $\mathrm{CO}$ was monitored at $40^{\circ} \mathrm{C}$ for 30 minutes and averaged. The rate was calculated as follows: 


$$
r_{C O 2}\left[\frac{m m o l}{\sec \times g_{P d}}\right]=\frac{\dot{N}_{C O, \text { in }} \times X_{C O, 40{ }^{\circ} \mathrm{C}}}{m_{P d}}
$$

where $r_{C O 2}$ is the rate of $\mathrm{CO}_{2}$ conversion, $\dot{N}_{C O \text {, in }}$ is the inlet molar flow rate of $\mathrm{CO}, X_{C O, 40{ }^{\circ} \mathrm{C}}$ is the conversion of $\mathrm{CO}$ at $40^{\circ} \mathrm{C}$ and $m_{P d}$ is the mass of Pd present in the catalyst.

\section{Characterization Methods}

Sample characterization was done using five techniques: transmission electron microscopy (TEM), X-ray energy dispersive spectroscopy (EDS), X-ray powder diffraction (XRD), BrunauerEmmett-Teller-derived $\mathrm{N}_{2}$ physisorption surface analysis (BET).

A Thermo Fisher Talos F200X G2 S/TEM was used for simultaneous conventional brightfield, dark-field and scanning transmission electron microscopy (STEM) imaging and EDS elemental mapping. The electron source was an X-FEG high-brightness Schottky-type emission gun. A Super-X windowless EDS detector was used to conduct EDS mapping. A JEOL 3100R05 double Cs corrected S/TEM was used for high-resolution aberration-corrected bright-field and high-angle annular dark-field imaging (HAADF). The electron source was a tungsten cold field emission tip.

A Rigaku 600 Miniflex operating with a current of $15 \mathrm{~mA}$, voltage of $40 \mathrm{kV}$, and step size of $0.01^{\circ}$ was used for XRD measurements. The Scherrer equation was used to approximate the size of $\mathrm{CeO}_{2}$ crystallites in $\mathrm{Pd} @ \mathrm{CeO}_{2}$ and $\mathrm{Pd} / \mathrm{CeO}_{2}$. The equation is as follows:

$$
\tau[n m]=\frac{K \cdot \lambda}{\beta \cdot \cos (\theta)}
$$

where $\tau$ is the mean feature size, $\mathrm{K}$ is a dimensionless shape factor (in this case taken as 0.9 ), $\lambda$ is the $\mathrm{x}$-ray wavelength $(1.54 \AA) \beta$ is the full width at half maximum of the peak characteristic for the crystallite and $\theta$ is the Bragg angle at said characteristic peak. The $\mathrm{CeO}_{2}$ (111) peak, centered at a $2 \theta$ of $\sim 28.5^{\circ}$, was used for $\mathrm{CeO}_{2}$ crystallite size approximation. ${ }^{67}$ The $\mathrm{Pd}$ (111) peak, which is centered at a $2 \theta$ of $\sim 40.4^{\circ}$ was used for Pd nanoparticle size approximation. ${ }^{68}$

A Micromeritics ASAP 2020 was used for BET surface area and pore distribution characterization. Prior to analysis, the samples were degassed at $350^{\circ} \mathrm{C}$ (achieved by a ramp of $20^{\circ} \mathrm{C} / \mathrm{min}$ ) for 8 hours. BET surface area analysis was conducted at $77 \mathrm{~K}$ using the amount of nitrogen adsorbed at various relative vapor pressures between $0.05 \leq \mathrm{P} / \mathrm{P}_{0} \leq 0.3$. The molecular cross-sectional area of nitrogen was assumed to be $0.1620 \mathrm{~nm}^{2}$ for the analysis. BET measurements were conducted in the low-pressure incremental dose mode to improve the resolution and accuracy of measurements.

Pulsed CO chemisorption similar to that reported by Takeguchi et al. ${ }^{69}$ was used to examine the Pd dispersion on initial and aged catalysts. The experiment was conducted on a Quantachrome ChemBET 3000. In this experiment, all gas flows were kept at $70 \mathrm{~mL} / \mathrm{min}$. The sample was first heated in $3 \% \mathrm{O}_{2}\left(\mathrm{~N}_{2}\right.$ balance) at $300^{\circ} \mathrm{C}$ for 1.5 hours prior to a system purge with flowing He. The sample was then kept at $300^{\circ} \mathrm{C}$ for 1.5 hours under the flow of $\mathrm{H}_{2}$ (Ar balance) to ensure completely reduce the catalyst. The sample was then cooled to $50^{\circ} \mathrm{C}$ under flowing $\mathrm{H}_{2}$ prior to a system purge with flowing He. $3 \% \mathrm{O}_{2}\left(\mathrm{~N}_{2}\right.$ balance) was flown over the sample for 5 minutes. The catalyst was then exposed to $1 \% \mathrm{CO}_{2}\left(\mathrm{~N}_{2}\right.$ balance) for 5 minutes. The system was exposed to a He purge prior to $\mathrm{H}_{2}$ gas flow for 10 minutes. The sample was then subjected to the pulsed $\mathrm{CO}$ chemisorption experiment. The number of molecules of $\mathrm{CO}$ chemisorbed per mass of catalyst was calculated as follows: 


$$
N_{C O}\left[\frac{\text { molecules }}{g}\right]=\frac{V_{C O} \cdot \rho_{C O} \cdot N_{A}}{M_{C O} \cdot m_{c a t}}
$$

where $V_{C O}$ is the total volume of chemisorbed $\mathrm{CO}, \rho_{C O}$ is the density of $\mathrm{CO}$ at the temperature used for the chemisorption experiment $\left(50^{\circ} \mathrm{C}\right), N_{A}$ is Avogadro's constant and $m_{c a t}$ is the mass of the catalyst used in the experiment. The metal dispersion was calculated from the number of molecules of chemisorbed $\mathrm{CO}$ by:

$$
\gamma[\%]=\frac{A \cdot M_{P d} \cdot N_{C O}}{100 \cdot W_{P d}}
$$

Where $A$ is the stoichiometric fitting factor that describes the chemisorption of $\mathrm{CO}$ on $\mathrm{Pd}$ surfaces (1 in this case), $M_{P d}$ is the molar mass of Pd, and $W_{P d}$ is the weight percent of Pd in the catalyst sample.

Thermogravimetric analysis of the $\mathrm{Pd} / \mathrm{CeO}_{2}$ and $\mathrm{Pd} @ \mathrm{CeO}_{2}$ catalysts was conducted before and after the first cycle of $800^{\circ} \mathrm{C}$ aging to quantitatively examine how thermally-induced restructuring affected the release of oxygen from the $\mathrm{CeO}_{2}$ lattice, which plays a role in mediating catalytic performance in oxidation reactions. A TA Q500 thermogravimetric analyser (TA Instruments) was used to perform the TGA experiments. According to previous work by Schwank et al. ${ }^{70}$ initial catalyst samples were loaded onto the TGA sample pan and pretreated under pure $\mathrm{N}_{2}$ gas flowing at $100 \mathrm{~mL} / \mathrm{min}$ for 1 hour at $300^{\circ} \mathrm{C}$, achieved with a ramp of $5^{\circ} \mathrm{C} / \mathrm{min}$. This was done to remove any adsorbed water from the catalyst. The catalyst was then cooled to $50^{\circ} \mathrm{C}$. Once the weight was stable at $50^{\circ} \mathrm{C}$, the gas flow was switched to a $4 \% \mathrm{H}_{2} / \mathrm{N}_{2}$ mixture (also at 100 $\mathrm{mL} / \mathrm{min}$ ) and the sample was kept at $50^{\circ} \mathrm{C}$ for 4 hours. The sample was then heated by $50^{\circ} \mathrm{C}$ with a ramp of $5^{\circ} \mathrm{C} / \mathrm{min}$, and left at $100^{\circ} \mathrm{C}$ for 4 hours. This process of ramping to the next temperature, point at intervals of $50^{\circ} \mathrm{C}$ and holding at each temperature point for 4 hours, was repeated until the temperature reached $600^{\circ} \mathrm{C}$. The amount of oxygen released at each temperature, normalized by the mass of catalyst, was calculated as follows:

$$
\mathrm{n}_{\mathrm{O}, \mathrm{c}}\left[\frac{\mathrm{mmol}}{\mathrm{g}_{\text {cat }}}\right]=\left(\frac{\overline{\mathrm{m}}_{\mathrm{T}, \mathrm{p}}-\overline{\mathrm{m}}_{\mathrm{T}, \mathrm{c}}[\mathrm{mg}]}{16\left[\frac{\mathrm{g}}{\mathrm{mol}}\right]}\right) \times \frac{1000\left[\frac{\mathrm{mg}}{\mathrm{g}}\right]}{\mathrm{m}_{\text {cat }}[\mathrm{mg}]}
$$

where $\mathrm{n}_{\mathrm{O}}$ is the mmol amount of oxygen released at the current temperature point, $\overline{\mathrm{m}}_{\mathrm{T}, \mathrm{p}}$ is the mass of the sample at the preceding temperature point averaged over its respective 4-hour dwelling period, $\overline{\mathrm{m}}_{\mathrm{T}, \mathrm{c}}$ is the mass of the sample at the current temperature point averaged over its respective 4-hour dwelling period and $\mathrm{m}_{\mathrm{cat}}$ is the mass of the catalyst used in the experiment, after the 1-hour pre-treatment at $300^{\circ} \mathrm{C}$ in pure $\mathrm{N}_{2}$.

X-ray photoelectron spectroscopy measurements were taken on a Kratos Axis Ultra XPS with a monochromatic $\mathrm{Al} \mathrm{x}$-ray source operating at $8 \mathrm{~mA}$ and $14 \mathrm{kV}$ to examine changes in oxidation state distribution in the O1s and Pd3d scan regions. XPS spectra were normalized relative to a In metal standard foil and deconvoluted using the CasaXPS software (see the Supporting Information for deconvolution details).

\section{AUTHOR INFORMATION}

Corresponding Authors

Andrej Lenert - University of Michigan, Ann Arbor, Michigan;

https://orcid.org/0000-0002-1142-6627; Email: alenert@ umich.edu 
Johannes W. Schwank - University of Michigan, Ann Arbor, Michigan; https://orcid.org/0000-0002-8218-5189; Email: schwank@umich.edu

Other Authors

Alexander J. Hill - University of Michigan, Ann Arbor, Michigan; https://orcid.org/0000-0003-0181-7920

Adarsh Bhat - University of Michigan, Ann Arbor, Michigan; https://orcid.org/0000-0002-1142-6731

Zachary J. Berquist - University of Michigan, Ann Arbor, Michigan

Galen B. Fisher - University of Michigan, Ann Arbor, Michigan;

https://orcid.org/0000-0003-4169-0602

Complete contact information is available at:

Author Contributions

A. J. H. designed and conducted the experiments, conducted data analysis and wrote the manuscript. A. B. assisted with experiments and manuscript review. Z. J. B. conducted XRD measurements. G. B. F. revised the manuscript. A. L. contributed to data analysis and revised the manuscript. J. W. S. contributed to data analysis and revised the manuscript. All authors have given approval to the final version of this manuscript.

Notes

The authors declare no competing financial interest.

\section{ACKNOWLEDGMENTS}

The authors acknowledge Dr. Tao Ma and Dr. Haiping Sun of the Michigan Center for Materials Characterization (MC2) for training and input regarding electron microscopy, EDS and XPS characterization. The authors acknowledge NSF awards DMR-0723032, DMR-0420785 and the College of Engineering, which support the instruments used at the MC2 facility. The authors acknowledge Dr. Chang Yup Seo and Dr. Xiaoyin Chen for their inputs.

\section{REFERENCES}

(1) He, J.-J.; Wang, C.-X.; Zheng, T.-T.; Zhao, Y.-K. Thermally Induced Deactivation and the Corresponding Strategies for Improving Durability in Automotive Three-Way Catalysts. Johnson Matthey Technol. Rev. 2016, 60, 196-203. https://doi.org/10.1595/205651316X691960.

(2) Datye, A. K.; Votsmeier, M. Opportunities and Challenges in the Development of Advanced Materials for Emission Control Catalysts. Nat. Mater. 2020. https://doi.org/10.1038/s41563-020-00805-3.

(3) Yao, X.; Wei, Y.; Wang, Z.; Gan, L. Revealing the Role of Surface Composition on the Particle Mobility and Coalescence of Carbon-Supported Pt Alloy Fuel Cell Catalysts by In Situ Heating (S)TEM. ACS Catal. 2020, 10, 7381-7388. 
https://doi.org/10.1021/acscatal.0c01765.

(4) Hansen, T. W.; DeLaRiva, A. T.; Challa, S. R.; Datye, A. K. Sintering of Catalytic

Nanoparticles: Particle Migration or Ostwald Ripening? Acc. Chem. Res. 2013, 46, 17201730. https://doi.org/10.1021/ar3002427.

(5) Argyle, M. D.; Bartholomew, C. H. Heterogeneous Catalyst Deactivation and

Regeneration: A Review. Catalysts 2015, 5, 145-269.

https://doi.org/10.3390/catal5010145.

(6) Yao, Y.; Huang, Z.; Xie, P.; Wu, L.; Ma, L.; Li, T.; Pang, Z.; Jiao, M.; Liang, Z.; Gao, J.; He, Y.; Kline, D. J.; Zachariah, M. R.; Wang, C.; Lu, J.; Wu, T.; Li, T.; Wang, C.; Shahbazian-Yassar, R.; Hu, L. High Temperature Shockwave Stabilized Single Atoms. Nat. Nanotechnol. 2019, 14, 851-857. https://doi.org/10.1038/s41565-019-0518-7.

(7) Xie, H.; Hong, M.; Hitz, E. M.; Wang, X.; Cui, M.; Kline, D. J.; Zachariah, M. R.; Hu, L. High-Temperature Pulse Method for Nanoparticle Redispersion. J. Am. Chem. Soc. 2020, 142, 17364-17371. https://doi.org/10.1021/jacs.0c04887.

(8) Sá, J.; Taylor, S. F. R.; Daly, H.; Goguet, A.; Tiruvalam, R.; He, Q.; Kiely, C. J.; Hutchings, G. J.; Hardacre, C. Redispersion of Gold Supported on Oxides. ACS Catal. 2012, 2, 552-560. https://doi.org/10.1021/cs300074g.

(9) Zhou, X.; Zhang, Y.; Wang, J. DFT Study on the Regeneration of $\mathrm{Pt} / \gamma-\mathrm{Al}_{2} \mathrm{O}_{3}$ Catalyst: The Effect of Chlorine on the Redispersion of Metal Species. Appl. Surf. Sci. 2021, 545 , 148988. https://doi.org/10.1016/j.apsusc.2021.148988.

(10) Jeong, H.; Lee, G.; Kim, B.-S.; Bae, J.; Han, J. W.; Lee, H. Fully Dispersed Rh Ensemble Catalyst To Enhance Low-Temperature Activity. J. Am. Chem. Soc. 2018, 140, 95589565. https://doi.org/10.1021/jacs.8b04613.

(11) Kunwar, D.; Zhou, S.; Delariva, A.; Peterson, E. J.; Xiong, H.; Pereira-Hernández, X. I.; Purdy, S. C.; Ter Veen, R.; Brongersma, H. H.; Miller, J. T.; Hashiguchi, H.; Kovarik, L.; Lin, S.; Guo, H.; Wang, Y.; Datye, A. K. Stabilizing High Metal Loadings of Thermally Stable Platinum Single Atoms on an Industrial Catalyst Support. ACS Catal. 2019, 9, 3978-3990. https://doi.org/10.1021/acscatal.8b04885.

(12) Choi, M. S.; Jeong, H.; Lee, H. Re-Dispersion of Pd-Based Bimetallic Catalysts by Hydrothermal Treatment for CO Oxidation. RSC Adv. 2021, 11, 3104-3109. https://doi.org/10.1039/D0RA09912K.

(13) Gawande, M. B.; Goswami, A.; Asefa, T.; Guo, H.; Biradar, A. V; Peng, D.-L.; Zboril, R.; Varma, R. S. Core-Shell Nanoparticles: Synthesis and Applications in Catalysis and Electrocatalysis. Chem. Soc. Rev. 2015, 44, 7540-7590. https://doi.org/10.1039/c5cs00343a.

(14) Gao, C.; Lyu, F.; Yin, Y. Encapsulated Metal Nanoparticles for Catalysis. Chem. Rev. 2021, 121, 834-881. https://doi.org/10.1021/acs.chemrev.0c00237.

(15) Seo, C. Y.; Chen, X.; Sun, K.; Allard, L. F.; Fisher, G. B.; Schwank, J. W. Palladium Redispersion at High Temperature within the Pd@SiO 2 Core@ shell Structure. Catal. Commun. 2018, 108, 73-76. https://doi.org/10.1016/j.catcom.2018.01.027.

(16) Hill, A. J.; Seo, C. Y.; Chen, X.; Bhat, A.; Fisher, G. B.; Lenert, A.; Schwank, J. W.

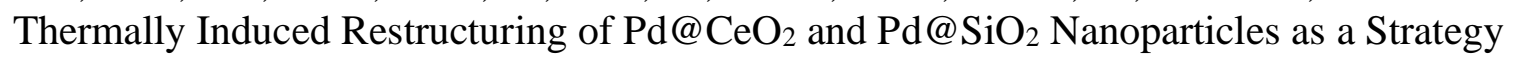
for Enhancing Low-Temperature Catalytic Activity. ACS Catal. 2020, 10, 1731 - 1741. https://doi.org/10.1021/acscatal.9b05224.

(17) Cargnello, M.; Doan-Nguyen, V. V. T.; Gordon, T. R.; Diaz, R. E.; Stach, E. A.; Gorte, R. J.; Fornasiero, P.; Murray, C. B. Control of Metal Nanocrystal Size Reveals Metal- 
Support Interface Role for Ceria Catalysts. Science. 2013, 341, 771-773.

https://doi.org/10.1126/science.1240148.

(18) Puigdollers, A. R.; Schlexer, P.; Tosoni, S.; Pacchioni, G. Increasing Oxide Reducibility: The Role of Metal/Oxide Interfaces in the Formation of Oxygen Vacancies. ACS Catal. 2017, 7, 6493-6513. https://doi.org/10.1021/acscatal.7b01913.

(19) Lee, J.; Theis, J. R.; Kyriakidou, E. A. Vehicle Emissions Trapping Materials: Successes, Challenges, and the Path Forward. Appl. Catal. B Environ. 2019, 243, 397-414. https://doi.org/10.1016/j.apcatb.2018.10.069.

(20) Trovarelli, A.; de Leitenburg, C.; Boaro, M.; Dolcetti, G. The Utilization of Ceria in Industrial Catalysis. Catal. Today 1999, 50, 353-367. https://doi.org/10.1016/S09205861(98)00515-X.

(21) Freund, H.-J.; Meijer, G.; Scheffler, M.; Schlögl, R.; Wolf, M. CO Oxidation as a Prototypical Reaction for Heterogeneous Processes. Angew. Chemie Int. Ed. 2011, 50, 10064-10094. https://doi.org/10.1002/anie.201101378.

(22) Choi, Y. S.; Moschetta, E. G.; Miller, J. T.; Fasulo, M.; McMurdo, M. J.; Rioux, R. M.; Tilley, T. D. Highly Dispersed Pd-SBA15 Materials from Tris(Tert-Butoxy)Siloxy Complexes of Pd(II). ACS Catal. 2011, 1, 1166-1177. https://doi.org/10.1021/cs2002719.

(23) Goldsmith, B. R.; Peters, B.; Johnson, J. K.; Gates, B. C.; Scott, S. L. Beyond Ordered Materials: Understanding Catalytic Sites on Amorphous Solids. ACS Catal. 2017, 7, 7543-7557. https://doi.org/10.1021/acscatal.7b01767.

(24) Pereira-Hernández, X. I.; DeLaRiva, A.; Muravev, V.; Kunwar, D.; Xiong, H.; Sudduth, B.; Engelhard, M.; Kovarik, L.; Hensen, E. J. M.; Wang, Y.; Datye, A. K. Tuning Pt-CeO 2 Interactions by High-Temperature Vapor-Phase Synthesis for Improved Reducibility of Lattice Oxygen. Nat. Commun. 2019, 10, 1358. https://doi.org/10.1038/s41467-01909308-5.

(25) Seo, C.; Yi, E.; Nahata, M.; Laine, R. M.; Schwank, J. W. Facile, One-Pot Synthesis of $\mathrm{Pd} @ \mathrm{CeO}_{2}$ Core@shell Nanoparticles in Aqueous Environment by Controlled Hydrolysis of Metalloorganic Cerium Precursor. Mater. Lett. 2017, 206, 105-108. https://doi.org/10.1016/j.matlet.2017.06.114.

(26) Huang, Y.; Pemberton, J. E. Synthesis of Uniform, Spherical Sub-100 Nm Silica Particles Using a Conceptual Modification of the Classic LaMer Model. Colloids Surfaces A Physicochem. Eng. Asp. 2010, 360, 175-183. https://doi.org/10.1016/j.colsurfa.2010.02.031.

(27) Cargnello, M.; Wieder, N. L.; Montini, T.; Gorte, R. J.; Fornasiero, P. Synthesis of Dispersible Pd@ $\mathrm{CeO}_{2}$ Core-Shell Nanostructures by Self-Assembly. J. Am. Chem. Soc. 2010, 132, 1402-1409. https://doi.org/10.1039/b916035c.(20).

(28) Duprat, F. Light-off Curve of Catalytic Reaction and Kinetics. Chem. Eng. Sci. 2002, 57, 901-911. https://doi.org/10.1016/S0009-2509(01)00409-2.

(29) Ye, J.; Cheng, D.; Chen, F.; Zhan, X. Controlled Synthesis of Sintering-Resistant $\mathrm{Pd} @ \mathrm{CeO}_{2}$ Core-Shell Nanotube Catalysts for $\mathrm{CO}$ Oxidation. Ind. Eng. Chem. Res. 2019, 58, 21972-21982. https://doi.org/10.1021/acs.iecr.9b04697.

(30) Peterson, E. J.; DeLaRiva, A. T.; Lin, S.; Johnson, R. S.; Guo, H.; Miller, J. T.; Hun Kwak, J.; Peden, C. H. F.; Kiefer, B.; Allard, L. F.; Ribeiro, F. H.; Datye, A. K. LowTemperature Carbon Monoxide Oxidation Catalysed by Regenerable Atomically Dispersed Palladium on Alumina. Nat. Commun. 2014, 5, 4885. https://doi.org/10.1038/ncomms5885. 
(31) Li, P.; Chen, X.; Li, Y.; Schwank, J. W. A Review on Oxygen Storage Capacity of $\mathrm{CeO}_{2-}$ Based Materials: Influence Factors, Measurement Techniques, and Applications in Reactions Related to Catalytic Automotive Emissions Control. Catal. Today 2019, 327, 90-115. https://doi.org/10.1016/j.cattod.2018.05.059.

(32) Alcala, R.; DeLaRiva, A.; Peterson, E. J.; Benavidez, A.; Garcia-Vargas, C. E.; Jiang, D.; Pereira-Hernández, X. I.; Brongersma, H. H.; Veen, R. ter; Staněk, J.; Miller, J. T.; Wang, Y.; Datye, A. K. Atomically Dispersed Dopants for Stabilizing Ceria Surface Area. Appl. Catal. B Environ. 2021, 284, 119722. https://doi.org/10.1016/j.apcatb.2020.119722.

(33) Su, Y.-Q.; Liu, J.-X.; Filot, I. A. W.; Hensen, E. J. M. Theoretical Study of Ripening Mechanisms of Pd Clusters on Ceria. Chem. Mater. 2017, 29, 9456-9462. https://doi.org/10.1021/acs.chemmater.7b03555.

(34) Jiang, D.; Wan, G.; García-Vargas, C. E.; Li, L.; Pereira-Hernández, X. I.; Wang, C.; Wang, Y. Elucidation of the Active Sites in Single-Atom $\mathrm{Pd}_{1} / \mathrm{CeO}_{2}$ Catalysts for LowTemperature CO Oxidation. ACS Catal. 2020, 10, 11356-11364. https://doi.org/10.1021/acscatal.0c02480.

(35) Xiong, H.; Datye, A. K.; Wang, Y. Thermally Stable Single-Atom Heterogeneous Catalysts. Adv. Mater. 2021, 2004319. https://doi.org/10.1002/adma.202004319.

(36) Martin, T. E.; Mitchell, R. W.; Boyes, E. D.; Gai, P. L. Atom-by-Atom Analysis of Sintering Dynamics and Stability of Pt Nanoparticle Catalysts in Chemical Reactions. Philos. Trans. R. Soc. A Math. Phys. Eng. Sci. 2020, 378, 20190597. https://doi.org/10.1098/rsta.2019.0597.

(37) Goodman, E. D.; Carlson, E. Z.; Dietze, E. M.; Tahsini, N.; Johnson, A.; Aitbekova, A.; Nguyen Taylor, T.; Plessow, P. N.; Cargnello, M. Size-Controlled Nanocrystals Reveal Spatial Dependence and Severity of Nanoparticle Coalescence and Ostwald Ripening in Sintering Phenomena. Nanoscale 2021, 13, 930-938. https://doi.org/10.1039/D0NR07960J.

(38) Wan, Q.; Hu, S.; Dai, J.; Chen, C.; Li, W.-X. First-Principles Kinetic Study for Ostwald Ripening of Late Transition Metals on $\mathrm{TiO}_{2}$ (110). J. Phys. Chem. C 2019, 123, 11601169. https://doi.org/10.1021/acs.jpcc.8b08530.

(39) Lieske, H.; Voelter, J. Palladium Redispersion by Spreading of Palladium(II) Oxide in Oxygen Treated Palladium/Alumina. J. Phys. Chem. 1985, 89, 1841-1842. https://doi.org/10.1021/j100256a001.

(40) Chen, X.; Schwank, J. W.; Fisher, G. B.; Cheng, Y.; Jagner, M.; McCabe, R. W.; Katz, M. B.; Graham, G. W.; Pan, X. Nature of the Two-Step Temperature-Programmed Decomposition of PdO Supported on Alumina. Appl. Catal. A Gen. 2014, 475, 420-426. https://doi.org/10.1016/j.apcata.2014.01.056.

(41) Lupescu, J. A.; Schwank, J. W.; Dahlberg, K. A.; Seo, C. Y.; Fisher, G. B.; Peczonczyk, S. L.; Rhodes, K.; Jagner, M. J.; Haack, L. P. Pd Model Catalysts: Effect of Aging Environment and Lean Redispersion. Appl. Catal. B Environ. 2016, 183, 343-360. https://doi.org/10.1016/j.apcatb.2015.10.018.

(42) Chin, Y. H. C.; García-Diéguez, M.; Iglesia, E. Dynamics and Thermodynamics of PdPdO Phase Transitions: Effects of Pd Cluster Size and Kinetic Implications for Catalytic Methane Combustion. J. Phys. Chem. C 2016, 120, 1446-1460. https://doi.org/10.1021/acs.jpcc.5b06677.

(43) Goodman, E. D.; Johnston-Peck, A. C.; Dietze, E. M.; Wrasman, C. J.; Hoffman, A. S.; Abild-Pedersen, F.; Bare, S. R.; Plessow, P. N.; Cargnello, M. Catalyst Deactivation via 
Decomposition into Single Atoms and the Role of Metal Loading. Nat. Catal. 2019, 2, 748-755. https://doi.org/10.1038/s41929-019-0328-1.

(44) Bonati, M. L. M.; Douglas, T. M.; Gaemers, S.; Guo, N. Synthesis, Characterization, and Catalytic Properties of Novel Single-Site and Nanosized Platinum Catalysts. Organometallics 2012, 31, 5243-5251. https://doi.org/10.1021/om200778r.

(45) Rimoldi, M.; Mezzetti, A. Site Isolated Complexes of Late Transition Metals Grafted on Silica: Challenges and Chances for Synthesis and Catalysis. Catal. Sci. Technol. 2014, 4, 2724-2740. https://doi.org/10.1039/C4CY00450G.

(46) Su, Y.-Q.; Filot, I. A. W.; Liu, J.-X.; Hensen, E. J. M. Stable Pd-Doped Ceria Structures for $\mathrm{CH}_{4}$ Activation and CO Oxidation. ACS Catal. 2018, 8, 75-80. https://doi.org/10.1021/acscatal.7b03295.

(47) Hinokuma, S.; Fujii, H.; Okamoto, M.; Ikeue, K.; Machida, M. Metallic Pd Nanoparticles Formed by $\mathrm{Pd}-\mathrm{O}-\mathrm{Ce}$ Interaction: A Reason for Sintering-Induced Activation for $\mathrm{CO}$ Oxidation. Chem. Mater. 2010, 22, 6183-6190. https://doi.org/10.1021/cm102355x.

(48) Lashina, E. A.; Slavinskaya, E. M.; Boronin, A. I. Low-Temperature Activity of $\mathrm{Pd} / \mathrm{CeO}_{2}$ Catalysts: Mechanism of CO Interaction and Mathematical Modelling of TPR-CO Kinetic Data. Chem. Eng. Sci. 2021, 244, 116812. https://doi.org/10.1016/j.ces.2021.116812.

(49) Lu, Y.; Thompson, C.; Kunwar, D.; Datye, A. K.; Karim, A. M. Origin of the High CO Oxidation Activity on $\mathrm{CeO} 2$ Supported Pt Nanoparticles: Weaker Binding of CO or Facile Oxygen Transfer from the Support? ChemCatChem 2020, 12, 1726-1733. https://doi.org/10.1002/cctc.201901848.

(50) Wang, M.; Shen, M.; Jin, X.; Tian, J.; Li, M.; Zhou, Y.; Zhang, L.; Li, Y.; Shi, J. Oxygen Vacancy Generation and Stabilization in $\mathrm{CeO}_{2-x}$ by $\mathrm{Cu}$ Introduction with Improved $\mathrm{CO}_{2}$ Photocatalytic Reduction Activity. ACS Catal. 2019, 9, 4573-4581. https://doi.org/10.1021/acscatal.8b03975.

(51) Yu, X.; Li, J.; Wei, Y.; Zhao, Z.; Liu, J.; Jin, B.; Duan, A.; Jiang, G. Three-Dimensionally Ordered Macroporous $\mathrm{Mn}_{\mathrm{x}} \mathrm{Ce}_{1-\mathrm{x}} \mathrm{O}_{\delta}$ and $\mathrm{Pt} / \mathrm{Mn}_{0.5} \mathrm{Ce}_{0.5} \mathrm{O}_{\delta}$ Catalysts: Synthesis and Catalytic Performance for Soot Oxidation. Ind. Eng. Chem. Res. 2014, 53, 9653-9664. https://doi.org/10.1021/ie500666m.

(52) Li, W. J.; Wey, M. Y. Design of a Thermally Resistant Core@ shell/Halloysite Catalyst with Optimized Structure and Surface Properties for a Pd-Only Three-Way Catalyst. Appl. Catal. A Gen. 2020, 602, 117732. https://doi.org/10.1016/j.apcata.2020.117732.

(53) Barth, C.; Laffon, C.; Olbrich, R.; Ranguis, A.; Parent, P.; Reichling, M. A Perfectly Stoichiometric and Flat $\mathrm{CeO}_{2}$ (111) Surface on a Bulk-like Ceria Film. Sci. Rep. 2016, 6, 21165. https://doi.org/10.1038/srep21165.

(54) Wang, T.; Tao, X.; Li, X.; Zhang, K.; Liu, S.; Li, B. Synergistic Pd Single Atoms, Clusters, and Oxygen Vacancies on $\mathrm{TiO}_{2}$ for Photocatalytic Hydrogen Evolution Coupled with Selective Organic Oxidation. Small 2021, 17, 2006255. https://doi.org/10.1002/smll.202006255.

(55) Tana; Zhang, M.; Li, J.; Li, H.; Li, Y.; Shen, W. Morphology-Dependent Redox and Catalytic Properties of $\mathrm{CeO}_{2}$ Nanostructures: Nanowires, Nanorods and Nanoparticles. Catal. Today 2009, 148, 179-183. https://doi.org/10.1016/j.cattod.2009.02.016.

(56) Lee, J.; Ryou, Y.; Chan, X.; Kim, T. J.; Kim, D. H. How Pt Interacts with $\mathrm{CeO}_{2}$ under the Reducing and Oxidizing Environments at Elevated Temperature: The Origin of Improved Thermal Stability of $\mathrm{Pt} / \mathrm{CeO}_{2}$ Compared to $\mathrm{CeO}_{2}$. J. Phys. Chem. C 2016, 120, 2587025879. https://doi.org/10.1021/acs.jpcc.6b08656. 
(57) Song, W.; Su, Y.; Hensen, E. J. M. A DFT Study of CO Oxidation at the $\mathrm{Pd}-\mathrm{CeO}_{2}(110)$ Interface. J. Phys. Chem. C 2015, 119, 27505-27511.

https://doi.org/10.1021/acs.jpcc.5b09293.

(58) Neitzel, A.; Figueroba, A.; Lykhach, Y.; Skála, T.; Vorokhta, M.; Tsud, N.; Mehl, S.; Ševčíková, K.; Prince, K. C.; Neyman, K. M.; Matolín, V.; Libuda, J. Atomically Dispersed Pd, Ni, and Pt Species in Ceria-Based Catalysts: Principal Differences in Stability and Reactivity. J. Phys. Chem. C 2016, 120, 9852-9862. https://doi.org/10.1021/acs.jpcc.6b02264.

(59) Spezzati, G.; Su, Y.; Hofmann, J. P.; Benavidez, A. D.; DeLaRiva, A. T.; McCabe, J.; Datye, A. K.; Hensen, E. J. M. Atomically Dispersed Pd-O Species on $\mathrm{CeO}_{2}$ (111) as Highly Active Sites for Low-Temperature CO Oxidation. ACS Catal. 2017, 7, 6887-6891. https://doi.org/10.1021/acscatal.7b02001.

(60) Stonkus, O. A.; Kardash, T. Y.; Slavinskaya, E. M.; Zaikovskii, V. I.; Boronin, A. I. Thermally Induced Structural Evolution of Palladium-Ceria Catalysts. Implication for CO Oxidation. ChemCatChem 2019, 11, 3505-3521. https://doi.org/10.1002/cctc.201900752.

(61) Hatanaka, M.; Takahashi, N.; Takahashi, N.; Tanabe, T.; Nagai, Y.; Suda, A.; Shinjoh, H. Reversible Changes in the Pt Oxidation State and Nanostructure on a Ceria-Based Supported Pt. J. Catal. 2009, 266, 182-190. https://doi.org/10.1016/j.jcat.2009.06.005.

(62) Colussi, S.; Gayen, A.; Farnesi Camellone, M.; Boaro, M.; Llorca, J.; Fabris, S.; Trovarelli, A. Nanofaceted Pd-O Sites in Pd-Ce Surface Superstructures: Enhanced Activity in Catalytic Combustion of Methane. Angew. Chemie Int. Ed. 2009, 48, 84818484. https://doi.org/10.1002/anie.200903581.

(63) Hatanaka, M.; Takahashi, N.; Tanabe, T.; Nagai, Y.; Dohmae, K.; Aoki, Y.; Yoshida, T.; Shinjoh, H. Ideal Pt Loading for a Pt/CeO2-Based Catalyst Stabilized by a Pt-O-Ce Bond. Appl. Catal. B Environ. 2010, 99, 336-342. https://doi.org/10.1016/j.apcatb.2010.07.003.

(64) Lardinois, T. M.; Bates, J. S.; Lippie, H. H.; Russell, C. K.; Miller, J. T.; Meyer, H. M.; Unocic, K. A.; Prikhodko, V.; Wei, X.; Lambert, C. K.; Getsoin, A. B.; Gounder, R. Structural Interconversion between Agglomerated Palladium Domains and Mononuclear Pd(II) Cations in Chabazite Zeolites. Chem. Mater. 2021, 33, 1698-1713. https://doi.org/10.1021/acs.chemmater.0c04465.

(65) Wang, X.; Liu, D.; Li, J.; Zhen, J.; Wang, F.; Zhang, H. $\gamma-\mathrm{Al}_{2} \mathrm{O}_{3}$ Supported Pd@ $\mathrm{CeO}_{2}$ Core@shell Nanospheres: Salting-out Assisted Growth and Self-Assembly, and Their Catalytic Performance in CO Oxidation. Chem. Sci. 2015, 6, 2877-2884. https://doi.org/10.1039/C4SC03854A.

(66) Liu, Y.; Wang, Q.; Wu, L.; Long, Y.; Li, J.; Song, S.; Zhang, H. Tunable Bimetallic Au$\mathrm{Pd} @ \mathrm{CeO}_{2}$ for Semihydrogenation of Phenylacetylene by Ammonia Borane. Nanoscale 2019, 11, 12932-12937. https://doi.org/10.1039/C9NR02953B.

(67) Jayakumar, G.; Irudayaraj, A. A.; Raj, A. D. Particle Size Effect on the Properties of Cerium Oxide $\left(\mathrm{CeO}_{2}\right)$ Nanoparticles Synthesized by Hydrothermal Method. Mech. Mater. Sci. Eng. J. 2017, 9, 2-7. https://doi.org/10.2412/mmse.3.4.481.

(68) Jin, Z.; Nackashi, D.; Lu, W.; Kittrell, C.; Tour, J. M. Decoration, Migration, and Aggregation of Palladium Nanoparticles on Graphene Sheets. Chem. Mater. 2010, 22, 5695-5699. https://doi.org/10.1021/cm102187a.

(69) Takeguchi, T.; Manabe, S.; Kikuchi, R.; Eguchi, K.; Kanazawa, T.; Matsumoto, S.; Ueda, W. Determination of Dispersion of Precious Metals on $\mathrm{CeO}_{2}-\mathrm{Containing} \mathrm{Supports.} \mathrm{Appl.}$ 
Catal. A Gen. 2005, 293, 91-96. https://doi.org/10.1016/j.apcata.2005.07.013.

(70) Li, P.; Chen, X.; Ma, L.; Bhat, A.; Li, Y.; Schwank, J. W. Effect of Ce and La Dopants in $\mathrm{Co}_{3} \mathrm{O}_{4}$ Nanorods on the Catalytic Activity of $\mathrm{CO}$ and $\mathrm{C}_{3} \mathrm{H}_{6}$ Oxidation. Catal. Sci. Technol. 2019, 9, 1165-1177. https://doi.org/10.1039/C8CY02460J. 